\title{
Trichodesmium physiological ecology and phosphate reduction in the western tropical South Pacific
}

\author{
Kyle R. Frischkorn ${ }^{1,2}$, Andreas Krupke ${ }^{3, a}$, Cécile Guieu ${ }^{4,5}$, Justine Louis ${ }^{4, b}$, Mónica Rouco ${ }^{2, c}$, \\ Andrés E. Salazar Estrada ${ }^{1}$, Benjamin A. S. Van Mooy ${ }^{3}$, and Sonya T. Dyhrman ${ }^{1,2}$ \\ ${ }^{1}$ Department of Earth and Environmental Sciences, Columbia University, New York, NY, USA \\ ${ }^{2}$ Lamont-Doherty Earth Observatory, Columbia University, Palisades, NY, USA \\ ${ }^{3}$ Department of Marine Chemistry and Geochemistry, Woods Hole Oceanographic Institution, Woods Hole, MA, USA \\ ${ }^{4}$ Sorbonne Université, CNRS, Laboratoire d'Océanographie de Villefranche, LOV, 06230 Villefranche-sur-mer, France \\ ${ }^{5}$ The Center for Prototype Climate Modeling, New York University in Abu Dhabi, Abu Dhabi, UAE \\ a present address: Thermo Fisher Scientific, Life Science Solutions, 180 Oyster Point Blvd., San Francisco, CA, USA \\ ${ }^{\mathrm{b}}$ present address: University Rennes 1, Saint-Brieuc, France \\ ${ }^{c}$ present address: K=1 Project, Center for Nuclear Studies, Columbia University, New York, NY, USA
}

Correspondence: Sonya T. Dyhrman (sdyhrman@1deo.columbia.edu)

Received: 30 March 2018 - Discussion started: 11 April 2018

Revised: 4 July 2018 - Accepted: 5 September 2018 - Published: 2 October 2018

\begin{abstract}
N}_{2}$ fixation by the genus Trichodesmium is predicted to support a large proportion of the primary productivity across the oligotrophic oceans, regions that are considered among the largest biomes on Earth. Many of these environments remain poorly sampled, limiting our understanding of Trichodesmium physiological ecology in these critical oligotrophic regions. Trichodesmium colonies, communities that consist of the Trichodesmium host and their associated microbiome, were collected across the oligotrophic western tropical South Pacific (WTSP). These samples were used to assess host clade distribution, host and microbiome metabolic potential, and functional gene expression, with a focus on identifying Trichodesmium physiological ecology in this region. Genes sets related to phosphorus, iron, and phosphorus-iron co-limitation were dynamically expressed across the WTSP transect, suggestive of the importance of these resources in driving Trichodesmium physiological ecology in this region. A gene cassette for phosphonate biosynthesis was detected in Trichodesmium, the expression of which co-varied with the abundance of Trichodesmium Clade III, which was unusually abundant relative to Clade I in this environment. Coincident with the expression of the gene cassette, phosphate reduction to phosphite and lowmolecular-weight phosphonate compounds was measured in Trichodesmium colonies. The expression of genes that en-
\end{abstract}

able use of such reduced-phosphorus compounds were also measured in both Trichodesmium and the microbiome. Overall, these results highlight physiological strategies employed by consortia in an undersampled region of the oligotrophic WTSP and reveal the molecular mechanisms underlying previously observed high rates of phosphorus reduction in Trichodesmium colonies.

\section{Introduction}

The oligotrophic oceans extend over approximately $70 \%$ of the Earth and are characterized by chronically low-nutrient concentrations that limit primary productivity (Moore et al., 2013). Within oligotrophic marine environments, $\mathrm{N}_{2}$ fixing microorganisms can serve as a source of "new" nitrogen that is bioavailable to other organisms. Among these marine diazotrophs, the colonial, filamentous cyanobacterium Trichodesmium plays a disproportionately large role in the cycling of carbon, phosphorus and nitrogen: it supplies fixed carbon through photosynthesis, was recently found to be a hotspot of phosphate reduction (Van Mooy et al., 2015), and has been estimated to be responsible for approximately half of the biologically fixed $\mathrm{N}_{2}$ in the ocean (Bergman et al., 2013; Capone et al., 1997). As such, the efficiency of the 
biological pump in sequestering carbon in the deep ocean is dependent in part on the distribution and activities of diazotrophic organisms like Trichodesmium, and an understanding of how this organism's physiology and ecology varies across diverse environments is a critical aspect of understanding present and future global biogeochemical cycles.

Diazotrophy frees Trichodesmium from nutrient limitation by nitrogen. As such, the distribution and activities of this cyanobacterium are predominantly influenced by the availability of phosphorus and iron in the surface ocean, which vary depending on the ocean basin and its proximity to the supply of these resources (Moore et al., 2013; Sohm et al., 2011). Evidence of the intense competition for phosphorus and iron is reflected in the suite of physiological strategies that this organism is known to employ. These strategies include the production of transporters and enzymes that take up and hydrolyse diverse organic and reduced-phosphorus compounds (Dyhrman et al., 2006; Orchard et al., 2009; Polyviou et al., 2015) and enable the uptake and storage of organic and inorganic iron (Polyviou et al., 2018; Snow et al., 2015). The genes encoding these functions are expressed in situ across diverse environments, indicating that competition for these resources is a critical aspect of Trichodesmium physiology (Chappell et al., 2012; Dyhrman et al., 2006; Rouco et al., 2018). Recent evidence from culture studies also suggests that Trichodesmium employs a unique set of physiological strategies to cope with co-limitation of phosphorus and iron that differs from that of either resource alone (Walworth et al., 2017).

Survival in oligotrophic environments might also be enabled by biological interactions within Trichodesmium colonies. Trichodesmium has long been known to occur with closely associated bacteria that are unique from those freeliving in the water column (Hmelo et al., 2012; Paerly et al., 1989). Recent evidence suggests that these interactions are ubiquitous and taxonomically conserved across ocean basins (Lee et al., 2017; Rouco et al., 2016b) and that this epibiotic bacterial community, referred to as the Trichodesmium microbiome, contains a large amount of metabolic potential that exceeds and complements that of the Trichodesmium host in populations from the western North Atlantic (Frischkorn et al., 2017). Coordinated gene expression patterns within the holobiont (Trichodesmium and its microbiome) suggest an interdependence of the microbiome on host-derived fixed carbon, $\mathrm{N}_{2}$ and vitamins and suggests microbiome respiration could create conditions that favour continued diazotrophy and photosynthesis (Frischkorn et al., 2018; Paerl and Bebout, 1988). The stability of these relationships in the future ocean is unknown, but they are likely to change. For example, incubation of cultured Trichodesmium colonies with an elevated carbon dioxide concentration resulted in significant changes in microbiome nutritional physiology (Lee et al., 2018). These microbiome changes have the potential to alter the amount of fixed $\mathrm{N}_{2}$ and carbon that transfer from the colony to the environment at large. Overall, the contin- ued appreciation of the importance of the microbiome in Trichodesmium ecology underscores that investigations must consider these microbial communities to be holobionts in order to fully understand and predict their role in the future environment.

Geochemical drivers of Trichodesmium distribution and $\mathrm{N}_{2}$ fixation are increasingly well characterized in regions of the ocean where either phosphorus or iron are limiting factors, such as the North Atlantic and North Pacific Subtropical Gyre (Rouco et al., 2018; Sañudo-Wilhelmy et al., 2001; Sohm et al., 2011). The western tropical South Pacific (WTSP) represents an understudied region of the world's oceans (Bonnet et al., 2018) with conditions characterized by chronically low concentrations of both iron and phosphate (Moore et al., 2013; Sohm et al., 2011). Despite low resources, this region can support high levels of $\mathrm{N}_{2}$ fixation, with rates exceeding $700 \mu \mathrm{mol} \mathrm{m}{ }^{-2} \mathrm{~d}^{-1}$, where this resource transfers across diverse ecological groups and ultimately supplies up $90 \%$ of the photic zone with new nitrogen (Bonnet et al., 2017; Caffin et al., 2018a, b). In this study, metagenomic and metatranscriptomic sequencing was leveraged along with taxonomic distribution, physiological activities, and geochemical measurements to better understand Trichodesmium physiological ecology in an undersampled but important region of the oligotrophic ocean.

\section{Materials and methods}

\subsection{Biogeochemical analyses}

Samples were collected across a transect of the western tropical South Pacific (WTSP) during the OUTPACE cruise (Oligotrophy to UITra-oligotrophy PACific Experiment, http: //dx.doi.org/10.17600/15000900, last access: 17 September 2018) aboard the RV L'Atalante during austral summer (February-April) of 2015 (Fig. 1, Moutin et al., 2017). Samples for nutrient analyses were collected using a titanium rosette mounted with 24 Teflon-coated 12L GoFlos and operated along a Kevlar cable. Samples were filtered directly from the GoFlos through $0.2 \mu \mathrm{m}$ cartridges (Sartorius Sartrobran-P-capsule with a $0.45 \mu \mathrm{m}$ prefilter and a $0.2 \mu \mathrm{m}$ final filter) inside a clean van and analysed for dissolved inorganic phosphorus (DIP) and total dissolved iron concentrations (DFe). DIP was analysed directly on board using a $2 \mathrm{~m}$ length liquid waveguide capillary cell (LWCC) made of quartz capillary following the method described in PulidoVillena et al. (2010). Briefly LWCC was connected to a spectrophotometer and the measurements were taken in the visible spectrum at $710 \mathrm{~nm}$. The $2 \mathrm{~m}$ length LWCC allowed for a detection limit of $1 \mathrm{nM}$ and a relative standard deviation of less than $10 \%$. DFe concentrations were measured by flow injection with online preconcentration and chemiluminescence detection using the exact protocol, instrument, and analytical parameters as described by Blain et al. (2008). 

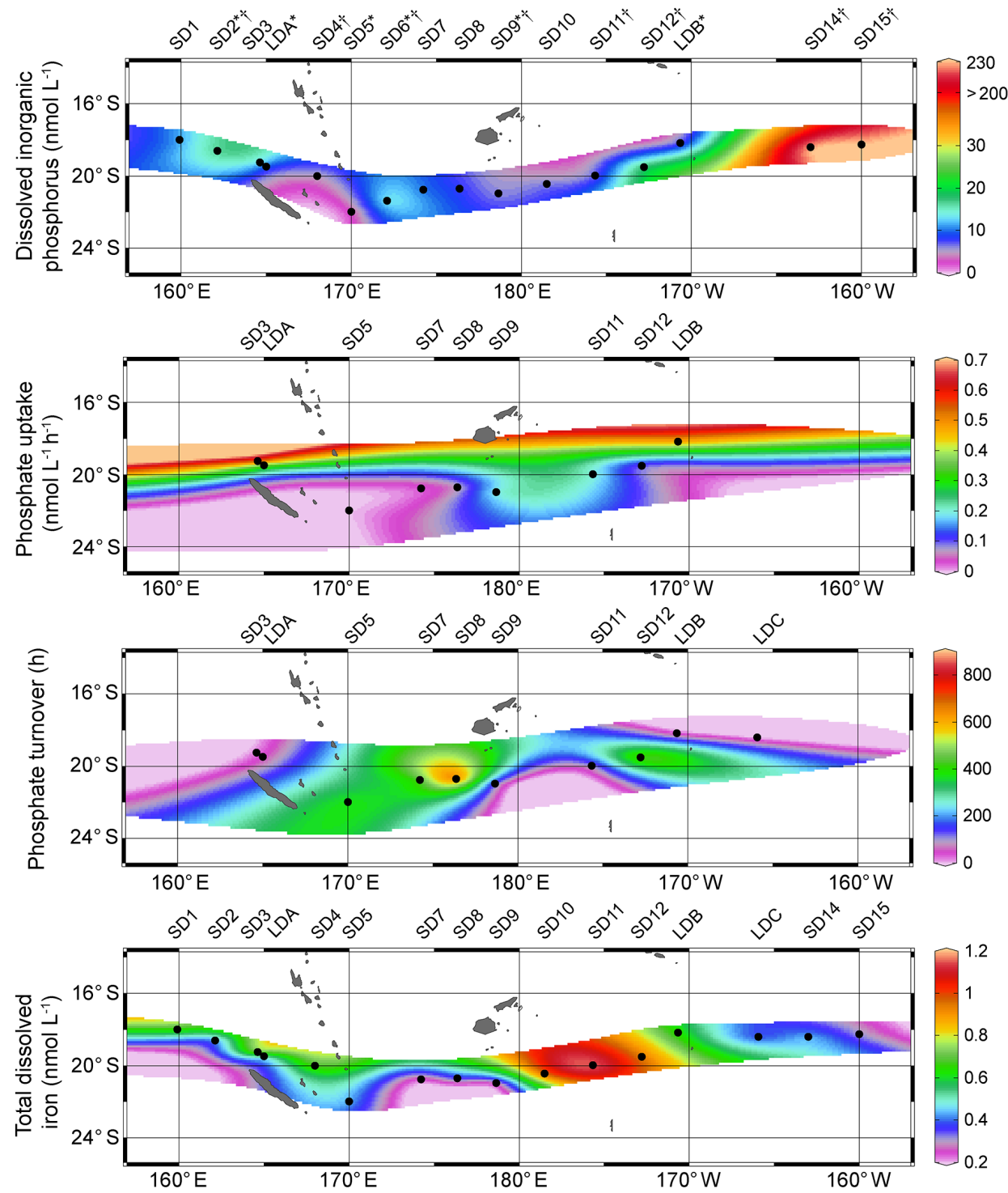

Figure 1. Surface water column dissolved inorganic phosphorus (DIP) concentration, community phosphate uptake rate, community phosphate turnover, and total dissolved iron concentration measured at stations across the OUTPACE (Oligotrophy to UlTra-oligotrophy PACific Experiment) transect during austral summer (February-April) of 2015. All samples were obtained from $10 \mathrm{~m}$ depth, with the exception of the DIP measurement from LDA and the DFe measurement from SD12 $(30 \mathrm{~m})$. Numbers above and below indicate the short-duration (denoted SD) or long-duration (denoted LDA, LDB, or LDC) stations where samples were obtained across the transect. In the top panel, ${ }^{*}$ indicates stations where metagenomic or metatranscriptomic samples were obtained and $\dagger$ indicates stations where Trichodesmium clade distribution samples were obtained.

Water column phosphate uptake rate was determined as described by Van Mooy et al. (2015) and is briefly outlined here. First, $50 \mathrm{~mL}$ aliquots of whole seawater collected in Niskin bottles were decanted into acid-washed polycarbonate vials. Next, $1 \mu \mathrm{Ci}$ of carrier-free ${ }^{33} \mathrm{P}$-phosphoric acid was added to the bottles, which represented an amendment of approximately $10 \mathrm{pmol} \mathrm{L}^{-1}$ of phosphoric acid. Then, bottles were incubated in an on-deck incubator for 2-4h. Finally, the seawater in the bottles was filtered through a $25 \mathrm{~mm}$ diameter, $0.2 \mu \mathrm{m}$ pore size polycarbonate membrane, and the radioactivity of the membrane was determined by liquid scintillation counting. The phosphate turnover rate in each incubation was calculated as the quotient of the ${ }^{33} \mathrm{P}$ radioactivity of the membrane and the total ${ }^{33} \mathrm{P}$ radioactivity of the amendment, divided by the duration of the incubation. The phosphate uptake rate was calculated as the product of the phosphate turnover and the DIP concentration. Data were visualized and contoured using Ocean Data View 4.6.2 with the DIVA grid method (http://odv.awi.de, last access: 17 September 2018). 


\subsection{Trichodesmium clade sampling and analysis}

Samples for Trichodesmium clade distribution analysis were obtained at selected short-duration stations across the transect from water depths ranging from $5 \mathrm{~m}$ to $\sim 150 \mathrm{~m}$ using $12 \mathrm{~L}$ of water for each depth obtained from a Rosette sampling device filtered through $47 \mathrm{~mm} 10 \mu \mathrm{m}$ pore size polycarbonate filters. Filters were flash frozen and stored in liquid nitrogen until processing. Absolute cell numbers in these samples were quantified following a previously described protocol (Rouco et al., 2014). Briefly, DNA was extracted from filters and the abundances of Trichodesmium Clade I (which encompasses T. thiebautii, T. tenue, T. hildebrandtii, and T. spiralis) and III (which encompasses T. erythraeum and $T$. contortum) were determined with quantitative polymerase chain reactions (qPCR) targeting the $r n p B$ gene using clade-specific primer sets (Chappell and Webb, 2010). Amplification of standards, no template controls (RNase-free water), and field samples were run in triplicate on a BioRad CFX96 Real-Time System C1000 Touch Thermal Cycler using Bio-Rad SYBR Green SuperMix (Bio-Rad Laboratories, Inc., Hercules, CA, USA). Standard curves were generated from DNA with known concentrations of T. erythraeum IMS101 and T. thiebautii VI-I. Concentrations were previously determined by 10 replicates of cell counting using a Sedgwick Rafter slide after Rouco et al. (2014). Reactions were run in final volumes of $25 \mu \mathrm{L}$, encompassing $12.5 \mu \mathrm{L}$ SuperMix, $2 \mu \mathrm{L}$ template, $9.5 \mu \mathrm{L}$ sterile water, and $200 \mathrm{nmol} \mathrm{L}^{-1}$ forward and reverse primers. Reaction conditions were as follows: $2 \mathrm{~min}$ at $50^{\circ} \mathrm{C}, 10 \mathrm{~min}$ at $95^{\circ} \mathrm{C}, 40 \mathrm{cy}$ cles of $15 \mathrm{~s}$ at $95^{\circ} \mathrm{C}$, and $1 \mathrm{~min}$ at $55^{\circ} \mathrm{C}$ with a fluorescence measurement. Resulting $\mathrm{C}_{\mathrm{T}} \mathrm{s}$, were averaged across the triplicates and compared against the standard curve to calculate the abundance of the rnpB gene, which we interpret as absolute cell number. Clade distribution data were displayed and contoured using Ocean Data View 4.6.2 with the DIVA grid method (http://odv.awi.de, last access: 17 September 2018).

\subsection{Trichodesmium colony sampling}

Trichodesmium colonies were sampled across the transect at approximately the same time (between 08:00 and 10:50 local time). Trichodesmium samples were obtained with six manual hauls of a $130 \mu \mathrm{m}$ mesh size net hand towed through surface seawater. The total time for six hauls of the net tow was approximately $15 \mathrm{~min}$ and likely filtered thousands of litres of seawater. Colonies were skimmed from the concentrated net tow sample with a Pasteur pipette from the surface layer of net towed samples and then washed 2 times with $0.2 \mu \mathrm{m}$ sterile-filtered surface seawater on $5 \mu \mathrm{m}, 47 \mathrm{~mm}$ polycarbonate filters with gentle vacuuming $(<170 \mathrm{mbar})$ to remove non-closely associated microorganisms. All colony samples were cleaned and processed within 15 min of collection. Filters with colonies were flash frozen and stored in liquid nitrogen for DNA or RNA extraction.

\subsection{Phosphate reduction in Trichodesmium colonies}

Phosphate uptake and synthesis rates of low-molecularweight (LMW) reduced-phosphate $(\mathrm{P}(+3))$ compounds in Trichodesmium colonies were determined as described by Van Mooy et al. (2015). Briefly, phosphate uptake by Trichodesmium colonies was determined by filling acid-washed polycarbonate $50 \mathrm{~mL}$ bottles with filter-sterilized surface seawater and approximately 20 Trichodesmium colonies. Incubation in on-deck incubators and measurement by liquid scintillation counting proceeded as described above for the whole water analysis. In parallel, to measure the synthesis rates of LMW $\mathrm{P}(+3)$ compounds, at stations SD2, LDA, SD9, SD11, and LDB Trichodesmium incubations were not immediately measured by liquid scintillation counting. Instead, colonies were placed in a cryovial containing $1 \mathrm{~mL}$ of pure water and flash frozen in liquid nitrogen. These samples were then transported ashore to the lab and subjected to numerous freeze-thaw cycles to extract intracellular LMW $\mathrm{P}(+3)$ compounds. The LMW $\mathrm{P}(+3)$ compounds in the extracts were then isolated by preparative anion chromatography. Two fractions were collected in retention time windows consistent with retention times of pure standards of (1) methylphosphonic acid, 2-hydroxy ethylphosphonic acid, and 2-amino ethylphosphonic acid; and (2) phosphorous acid. The ${ }^{33} \mathrm{P}$ radioactivity in these two operationally defined fractions is ascribed to LMW phosphonates and phosphite.

\subsection{DNA extraction and metagenome sequencing}

Genomic DNA was extracted from Trichodesmium colony samples ( $\sim 40$ colonies per sample) obtained from 1 day each during LDA and LDB, as well as at station SD5 (Fig. 1) using the MoBio Power Plant Pro DNA Isolation Kit (MoBio Laboratories, Inc., Carlsbad, CA, USA) following the manufacturer's instructions. Genomic DNA extracts were sequenced at the Argonne National Lab (Lemont, IL, USA) following a Trichodesmium consortium protocol previously described (Frischkorn et al., 2017). Briefly, DNA was sheared with a Covaris Sonicator (Woburn, MA, USA), transformed into libraries with WaferGen Apollo324 automated library system (Clonetech Laboratories, Mountain View, CA, USA) and Illumina compatible PrepX ILMN DNA kits (San Diego, CA, USA) following manufacturer's instructions. An average insert size of $\sim 750$ base pairs was targeted. Sage BluePippin (Beverly, MA, USA) was used to size-select libraries prior to sequencing all three samples split across one $2 \times 100 \mathrm{bp}$ lane of the Illumina HiSeq2000. Metagenomic reads from these three samples are available on the NCBI Sequence Read Archive under BioProject number PRJNA435427. 


\subsection{Metagenomic sequence assembly and analysis}

Raw reads were trimmed and assembled into scaffolds and subsequently analysed following the protocol previously reported in Frischkorn et al. (2017) and summarized here in an assembly and analysis methods pipeline (Supplement Fig. 1). Briefly, reads were trimmed with Sickle (https://github.com/ najoshi/sickle, last access: 17 September 2018), converted into fasta format, merged together, and co-assembled with IDBA-UD (Peng et al., 2012) so as to create a South Pacific Trichodesmium holobiont genomic template to which future metatranscriptomic reads could be mapped. Assembled scaffolds were partitioned between Trichodesmium and heterotrophic bacteria (hereafter referred to as the microbiome) and clustered into genome bins using MaxBin 2.0 with default parameters ( $\mathrm{Wu}$ et al., 2015). The taxonomic partitioning of binned scaffolds was carried out after translation of each scaffold into protein-coding genes with the metagenomic setting of Prodigal (Hyatt et al., 2010), annotation of resultant proteins with the blastp program of DIAMOND (Buchfink et al., 2015) against the NCBI nr database, and classification with MEGAN6 (Huson et al., 2013) based on the phylogenetic classification of the majority of proteins within a genome bin. Scaffolds from bins identified as non-Trichodesmium cyanobacteria or eukaryotes were excluded from further analyses. Functional annotations for translated proteins in the Trichodesmium and microbiome-identified genome bins were obtained by DIAMOND against the UniRef90 database (Suzek et al., 2007) with an e-value cut-off of $1 \times 10^{-3}$. Functional annotation was also carried out using the Kyoto Encyclopedia of Genes and Genomes (KEGG) with the online Automatic Annotation Server using the bidirectional best-hit method, the GHOSTX search program, and the prokaryote representative gene set options. KEGG definitions were obtained from the modules within the "pathway module" and "structural complex" categories and the submodules therein (available at https://www.genome.jp/kegg-bin/get_htext?ko00002.keg, last access: 17 September 2018).

Proteins from the merged assembly were also clustered into gene families of similar function or orthologous groups (OGs) following a previously reported pipeline (Frischkorn et al., 2017; Supplement Fig. 1). Briefly, reciprocal blasts of translated proteins greater than 70 amino acids were carried out with the DIAMOND blastp program. The blast results were processed using the program MCL (Markov cluster algorithm) set to an inflation parameter or 1.4. UniRef was used for the consensus functional annotation of each OG. The final UniRef annotation and KEGG annotations for each OG represent the individual annotation that the majority of proteins within that OG were assigned to. Homologs to the phosphonate biosynthesis gene phosphoenolpyruvate phosphomutase ( $\mathrm{ppm}$ ) were found by screening against manually annotated and reviewed Ppm proteins from the Swiss-Prot database. These verified proteins were aligned with Muscle version 3.8.425 with default parameters (Edgar, 2004), converted into HMM profiles with hmmbuild and hmmpress and used as the database for hmmsearch, all using HMMER version 3.1 (Eddy, 1995). This HMMER approach was used to screen proteins generated from this study, as well as a previously published Trichodesmium consortia metagenome assembly from the western tropical North Atlantic Ocean (Frischkorn et al., 2017) and protein sequences derived from the genome sequence of Trichodesmium erythraeum IMS101 (https://genome.jgi.doe.gov/portal/TrieryIMS101_ FD/TrieryIMS101_FD.info.html, last access: 17 September 2018). Sequence alignments were visualized using Geneious version 11.0.3 (http://www.geneious.com/, last access: 17 September 2018, Kearse et al., 2012) and important residues were obtained from previous crystal structure analyses (Chen et al., 2006). Trichodesmium-identified bins were reassembled to lengthen scaffolds in an attempt to provide genomic context to the ppm-containing scaffold. The subset of all metagenomic reads mapping to Trichodesmium bins was selected using Samtools (Li et al., 2009) and the subseq program in Seqtk (https://github.com/lh3/seqtk, last access: 17 September 2018) and then reassembled using IDBA-UD as described previously. Maximum likelihood phylogenetic analysis of $\mathrm{Ppm}$ and related proteins was performed using the FastTree plugin in Geneious with default settings (Price et al., 2010), following a protocol previously employed for the annotation of environmental Ppm proteins (Yu et al., 2013). The sequences used to generate the tree were composed of proteins with homology to the identified Trichodesmium Ppm proteins, as well as similar sequences pulled from the NCBI $\mathrm{nr}$ database after online blastp analysis. The Interactive Tree of Life program was used to edit phylogenetic trees (Letunic and Bork, 2016). Proteins were also screened for MpnS, a protein that produces methylphosphonate, using the same protocol described above.

\subsection{RNA extraction and metatranscriptomic sequencing}

Prokaryotic RNA was extracted and sequenced from Trichodesmium colony samples obtained from SD2, SD6, and SD9 as well as colonies collected on 3 separate days at LDB ( $\sim 40$ colonies per sample) (Fig. 1) following a protocol described previously (Frischkorn et al., 2018). Briefly, the QIAGEN RNeasy Mini Kit (QIAGEN, Hildern, Germany) was used to extract total RNA following the manufacturer's instructions, with the addition of $5 \mathrm{~min}$ of bead beating with $\sim 500 \mu \mathrm{L} 0.5 \mathrm{~mm}$ zirconia/silica beads after addition of Buffer RLT. On column DNase digestion (RNase-free DNase Kit, QIAGEN) was performed. A MICROBEnrich Kit (ThermoFisher Scientific, Waltham, MA, USA) was used to enrich the prokaryotic RNA fraction and ribosomal RNA was removed with the Ribo-Zero Magnetic Kit for bacteria (Illumina), both following the manufacturer's instructions. Concentration and integrity of mRNA was assessed using a Bio- 
Analyzer and the RNA 600 Nano Kit (Agilent Technologies, Santa Clara, CA, USA). Library preparation and sequencing was carried out at the JP Sulzberger Genome Center at Columbia University. Libraries were generated with the Illumina TruSeq RNA sample preparation kit. Samples were chemically fragmented using the Fragment, Prime, Finish Mix reagent (Illumina), which generates fragments of 140 220 bp. An Illumina HiSeq 2500 was used to sequence 60 million paired-end $100 \mathrm{bp}$ reads for each sample. Metatranscriptomic reads from these six samples are available on the NCBI Sequence Read Archive under BioProject number PRJNA435427.

\subsection{Metatranscriptomic sequence analysis}

Metatranscriptomic reads were trimmed, normalized, and mapped as previously described (Frischkorn et al., 2018) and are summarized in the analysis and assembly pipeline (Supplement Fig. 1). Briefly, raw reads were pre-processed following the Eel Pond Protocol for mRNAseq (Brown et al., 2013). Cleaned reads were mapped with RSEM (paired-end and bowtie2 options selected) ( $\mathrm{Li}$ and Dewey, 2011) to the protein-coding regions of the metagenomic scaffolds previously partitioned across Trichodesmium and the microbiome with an average of 10 million reads mapping per sample. Read counts were summed separately for Trichodesmium and microbiome fractions for all genes in an OG. Counts were normalized in each sample by calculating the transcript reads mapped per million (TPMs) separately for the Trichodesmium and microbiome fractions. In each sample, percentages of reads recruiting to KEGG submodules were normalized individually, and for Trichodesmium and the microbiome separately. KEGG heat maps are visualized as rowwide averages for each submodule. Comparisons of relative enrichment across sets of nutrient responsive genes were made using Kolmogorov-Smirnov tests to examine the null hypothesis that the expression of gene sets at a given station did not deviate significantly from the average expression of that set across the transect. Prior to testing, TPM expression values for each OG were normalized to the average abundance of that OG across the six samples. This normalization equalized the relative contribution of individual OGs to the gene set as a whole, thereby avoiding bias caused by highly expressed individual OGs. $P$ values less than 0.05 were considered significant. Pairwise correlation coefficients between clade abundance, phosphate, and OG expression (TPMs) were calculated using the cor function in $R$, and $p$ values less than 0.05 were considered significant. In the case of the OG expression, LDB samples from separate days were averaged. The data did not span enough coincident samples to do pairwise correlations between OG expression and iron. Trichodesmium OG TPMs were hierarchically clustered with the Broad Institute Morpheus program (https://software.broadinstitute.org/morpheus/, last access: 17 September 2018) using the "one minus Pearson correlation" metric and the "average" linkage method. Only OGs with an average expression greater than 2 TPM across all samples were included in this analysis.

\section{Results}

\subsection{Biogeochemistry}

Across the study transect the DIP concentration in surface water $(10 \mathrm{~m}$ depth, with the exception of the sample from LDA which was collected at $30 \mathrm{~m}$ ) ranged between 2.3 and $230 \mathrm{nmol} \mathrm{L}^{-1}$ (Fig. 1, Supplement Table 1) and averaged $36 \mathrm{nmol} \mathrm{L}^{-1}$. The phosphate turnover time in the water column microbial community was variable across the transect ranging between approximately 2 and $800 \mathrm{~h}$ (Fig. 1, Supplement Table 1), averaging $\sim 220 \mathrm{~h}$ across all stations sampled. The water column phosphate uptake rate was similarly variable, ranging from 0.006 to $0.68 \mathrm{nmol} \mathrm{L}^{-1} \mathrm{~h}^{-1}$, with lower uptake measured at stations where turnover time was high and vice versa (Fig. 1). Iron concentrations in the surface water $(10 \mathrm{~m}$ depth, with the exception of the sample from $\mathrm{SD} 12$, which was collected at $30 \mathrm{~m}$ ) ranged between 0.21 and $1.16 \mathrm{nmol} \mathrm{L}^{-1}$ (Fig. 1, Supplement Table 1) and averaged $0.6 \mathrm{nmol} \mathrm{L}^{-1}$.

\subsection{Trichodesmium clade distribution}

Trichodesmium (combined cell counts of Clade I and Clade III) was detected at every station and at all depths sampled across the transect with a maximum estimated concentration of over 172000 cells $\mathrm{L}^{-1}$ at $11 \mathrm{~m}$ at SD6 (Fig. 2a). Overall, abundance was markedly greater at the stations in the western half of the transect (stations west (left) of $170^{\circ} \mathrm{W}$ and LDB (Fig. 2a). In this western region of the transect, Trichodesmium was concentrated in the surface ocean between approximately 5 and $20 \mathrm{~m}$ depth, where the average concentration was $\sim 53000$ cells $L^{-1}$. To the east (right) of station LDB and the transition into the ultra-oligotrophic region, the concentration of Trichodesmium dropped and the average concentration at the surface between approximately 5 and $20 \mathrm{~m}$ was 75 cells $\mathrm{L}^{-1}$ (Fig. 2a). All cell counts are provided in Supplement Table 2. In addition to overall abundance of Trichodesmium, the contribution of Clade I (T. thiebautii, T. tenue, T. hildebrandtii, and T. spiralis) and Clade III (T. erythraeum and T. contortum) to the total Trichodesmium abundance at each station was determined (Fig. 2b). Across the transect, the Trichodesmium communities were dominated by Clade I, which made up approximately $80 \%$ of the cells measured on average at each station, while Clade III made up approximately $20 \%$ on average (Fig. 2b). Although Clade I was dominant overall, the percentage of Clade III rose to nearly $50 \%$ of the measured Trichodesmium community in some samples, and was highest between 4 and $40 \mathrm{~m}$ at SD4, SD6, and SD11 (Fig. 2b). Clade III was not detected at 

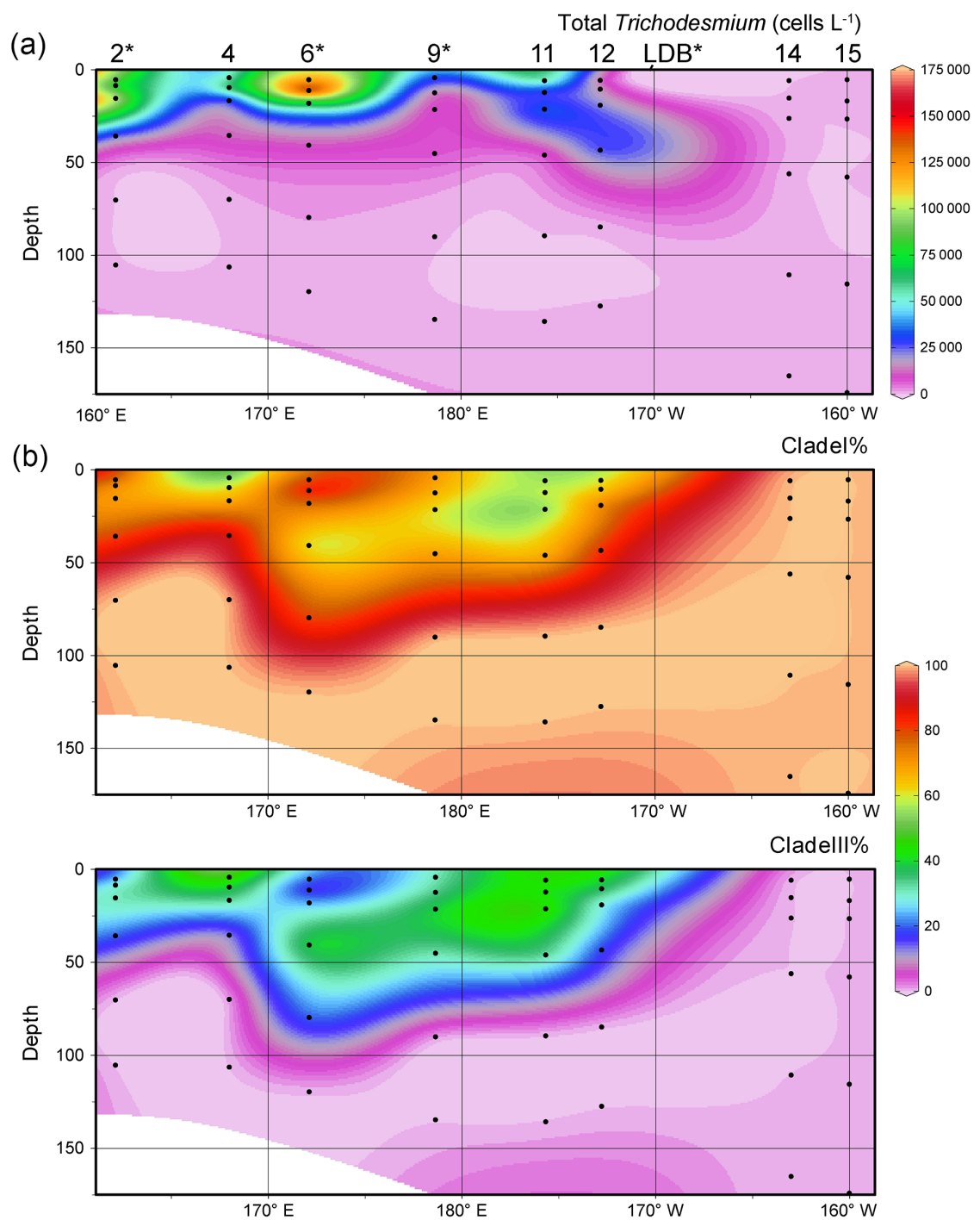

Figure 2. Abundance and clade distribution of Trichodesmium. Black dots denote the depths at which samples were taken, while station numbers are indicated above the panels. (a) Concentration of total Trichodesmium cells estimated from $\mathrm{qPCR}_{\text {of }}$ the $r n p B$ gene (cells $\mathrm{L}^{-1}$ ). (b) Relative proportion of Trichodesmium Clade I and Clade III across the transect. Clade I includes T. thiebautii, T. tenue, T. hildebrandtii, and $T$. spiralis. Clade III includes T. erythraeum and T. contortum. ${ }^{*}$ indicates stations where metatranscriptomic sequences were sampled. Clade samples were not obtained at LD stations.

any depth in the ultra-oligotrophic subtropical gyre stations (SD14 and SD15) (Fig. 2b).

\subsection{Metagenomic characterization of WTSP Trichodesmium consortia}

A merged metagenomic assembly of Trichodesmium consortia reads from selected stations across the OUTPACE transect (Fig. 1) yielded 801858 scaffolds in total. Taxonomic binning partitioned scaffolds into 48 genome bins with similar read coverage and tetranucleotide frequency. After phylogenetic analysis with MEGAN6, 18 of the bins were classified as Trichodesmium, 23 as heterotrophic bacteria, while the remaining bins had the majority of their pro- teins phylogenetically classified as Eukaryotes or other photosynthetic cyanobacteria. Subsequently, all Trichodesmiumidentified scaffolds were merged and considered the sampled Trichodesmium fraction of the WTSP consortia. Similarly, all heterotrophic bacteria-identified bins were merged together and considered the microbiome fraction. Together, these taxonomically verified scaffolds were translated into 198156 proteins, which clustered into 75530 gene families of putatively similar function or orthologous groups (OGs). Within the WTSP consortia, Trichodesmium and their microbiome possessed 9790 and 68538 OGs. Each OG likely represents a unique function or variant of a gene, as the majority of key functions examined subsequently were represented by 
one OG. The majority of these OGs were unique to the microbiome, with $2798(3.7 \%)$ of the total OGs composed of proteins found in both the Trichodesmium and microbiome genome bins.

Functional annotation of OGs showed that the microbiome contained nearly 10 times more unique KEGG IDs (Supplement Fig. 2). The greatest differences in functional gene capacity between Trichodesmium and the microbiome were found in the Environmental Information Processing and Carbohydrate and Lipid Metabolism modules (Supplement Fig. 2). Unique microbiome KEGG submodules included glycan, fatty acid, and carbohydrate metabolism functions. In the Environmental Information Processing category the microbiome possessed unique functions pertaining to peptide, nickel, phosphate, amino acid, and $\mathrm{ABC}$ transporters as well as an enrichment in proteins related to bacterial secretion systems (Supplement Fig. 2).

\subsection{Expression profiling of WTSP Trichodesmium consortia}

A total of 7251 Trichodesmium OGs and 21529 microbiome OGs recruited metatranscriptome reads from at least one sample. Hierarchical clustering of expression patterns in KEGG-annotated OGs identified variable patterns in Trichodesmium and the microbiome gene expression over space and time (Fig. 3). Submodules in the carbohydrate and lipid metabolism, genetic information processing, and nucleotide and amino acid metabolism modules had elevated expression in the SD stations relative to LDB. Similar patterns were generally observed in the expression of microbiome modules, most strikingly in the nucleotide and amino acid metabolism and environmental information processing modules. In Trichodesmium, exceptions to the trend included OGs in the ATP synthesis, nitrogen metabolism, phosphate and amino acid transport, two-component regulatory systems, and certain amino acid metabolism submodules, all of which had elevated relative expression during the 3 days of samples from LDB (Fig. 3). Summed TPM for each OG in the Trichodesmium and microbiome fractions along with their most abundant UniRef annotations are provided in Supplement Table 3 .

Hierarchical clustering of expression patterns in Trichodesmium OGs identified shifts in Trichodesmium gene expression from station to station, and over the 3 days of sampling at LDB (Fig. 4a). The nitrogenase enzyme subunit nifH OG peaked at SD2 (Fig. 4a), while a RuBisCO OG peaked at LDB 1 (Fig. 4a). The expression of Trichodesmium OGs known to be responsive to low-nutrient conditions also showed variation in the expression pattern across the transect (Fig. 4a). The low-phosphorus (low-P) responsive set was composed of OGs previously shown to have increased levels of gene expression under conditions of phosphate stress and included the alkaline phosphatases phoA (Tery_3467) and phoX (Tery_3845; proteins identified as PhoX clustered into two separate OGs, as has been previously observed in natural populations of Trichodesmium; Rouco et al., 2018), the highaffinity phosphate binding protein $s p h X$ (which is homologous to and clustered into one OG with $p s t S$ ) (Tery_3534), phosphite dehydrogenase $p t x D$ (Tery_0368) and the carbonphosphorus lyase gene marker phnJ (Tery_5000) (Dyhrman et al., 2006; Orchard et al., 2009; Polyviou et al., 2015). The low-iron (low-Fe) responsive set included OGs previously shown to have increased the transcript or protein expression in experimental low-iron cultures and in situ in lowiron environments and included the flavodoxins $f l d 1$ and $f l d 2$, which clustered into the same OG (Tery_1666, Tery_2559), fructose bisphosphate aldolase class II $f b a A$ (Tery_1687), the iron-stress-induced gene isiA (Tery_1667), and the irondeficiency-induced gene idiA (Tery_3377) (Chappell et al., 2012; Chappell and Webb, 2010; Snow et al., 2015; Webb et al., 2001). Also assayed were a suite of OGs recently shown to be significantly enriched in cultures of $T$. erythraeum IMS101 following prolonged maintenance in colimiting concentrations of phosphorus and iron (herein called the co-limitation responsive set) (Walworth et al., 2017). These OGs included the flavin-containing monoxygenase FMO (Tery_3826) that hydrolyses organic nitrogen, the 5methyltetrahydropteroyltriglutamate-homocysteine methyltransferase metE (Tery_0847), the 3-dehydroquinate synthase $a r o B$ (Tery_2977), and beta-ketoacyl synthase (OXSM, Tery_3819, and Tery_3821, which clustered into one OG). All OGs included in the three nutrient responsive Trichodesmium sets were expressed at each station. In general, low-P and low-Fe responsive gene set expression patterns tracked together from sample to sample. Two exceptions to this trend were the alkaline phosphatase phoA and the phosphonate lyase phnJ (Fig. 4a). There were no significant correlations between the low-P responsive OGs and the phosphate concentration. The majority of the OGs ( $\operatorname{aroB}, \operatorname{met} E$, $F M O$ ) in the co-limitation responsive set had similar expression patterns to the majority of the low-P responsive set, with the exception of OXSM (Fig. 4a). Expression of the RuBisCO OG was also modulated with this pattern (Fig. 4a). The expression of the nifH OG tracked with the low-Fe responsive set as well as phoA, and OXSM (Fig. 4a).

The relative enrichment of the low-P responsive gene set, low-Fe responsive gene set, and co-limitation gene set were examined from station to station, and over the 3 days of sampling at LDB using Kolmogorov-Smirnov tests (Fig. 4b) This approach estimated enrichment based on normalized expression levels of the resource responsive genes at individual stations relative to the average expression of the set across all stations sampled. In testing enrichment of the low-P responsive set, only the four OGs with expression patterns clustered together across the transect (Fig. 4a) were used. The signal of the low-P responsive set was significantly enriched during the first day sampled at LDB, while the signal in the low-Fe responsive set was significantly enriched at SD2 (Fig. 4b). The co-limitation set was not found to significantly deviate 


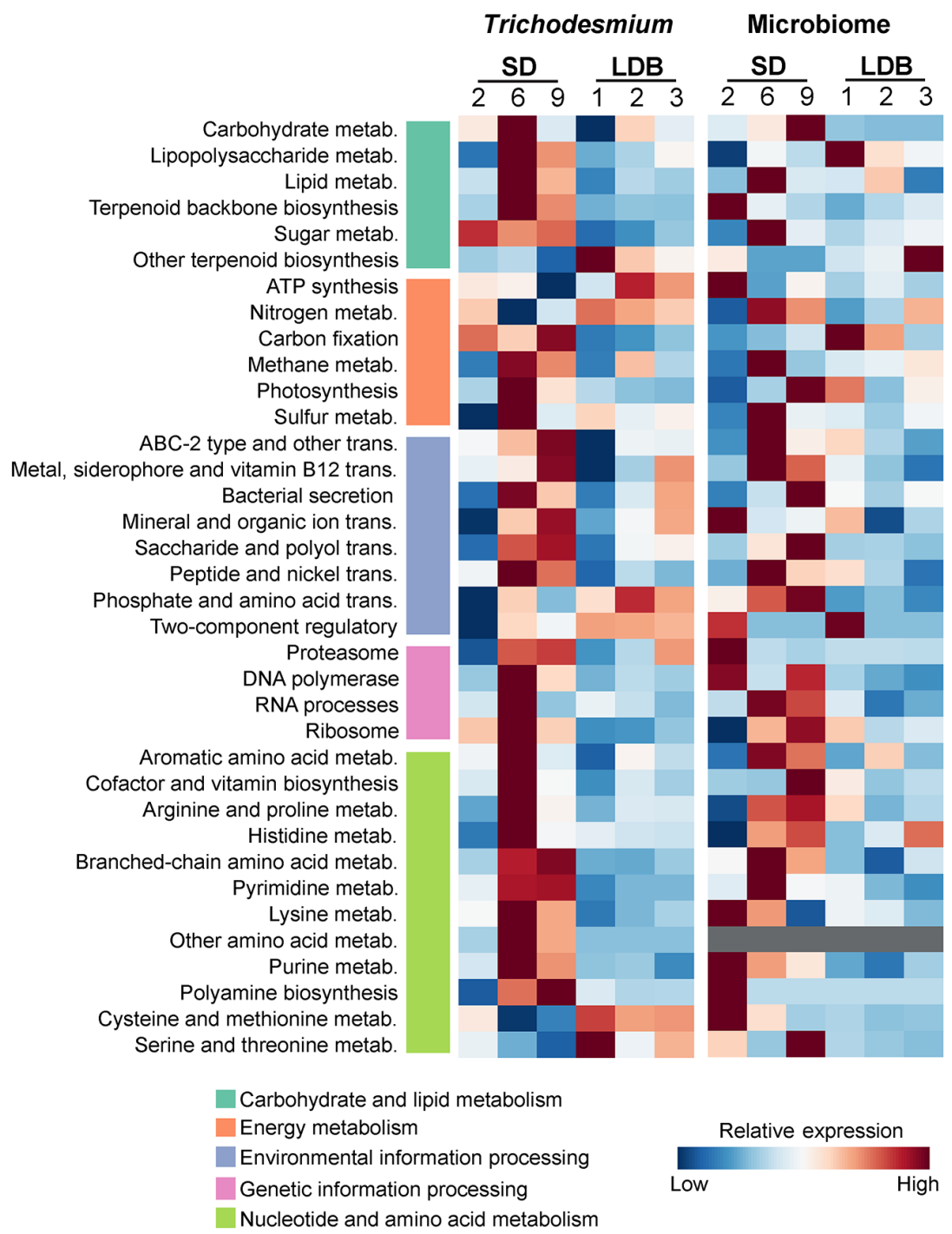

Figure 3. Heat map of the summed relative expression of Trichodesmium and microbiome orthologous groups (OGs) belonging to KEGG modules (large categories) and submodules at the short-duration (SD) stations and over 3 days at the long-duration (LDB) stations. Relative expression values are normalized to row averages for either Trichodesmium or the microbiome for that particular OG. The carbohydrate and lipid metabolism module was simplified as follows: carbohydrate metabolism is the sum of carbohydrate metabolism, central carbohydrate metabolism, glycan metabolism, and other carbohydrate metabolism submodules; lipid metabolism is the sum of fatty acid and lipid metabolism submodules. The genetic information processing module was simplified as follows: RNA processes is the sum of the RNA processing and RNA polymerase submodules. No microbiome OGs were detected in the other amino acid metabolism submodules.

from the average expression levels at any station sampled, although the overall pattern in expression was similar to that of the low-P responsive set (Fig. 4b).

\subsection{Evidence of phosphonate biosynthesis in Trichodesmium}

A $\sim 7400$ bp scaffold containing a cassette of genes encoding a phosphonate biosynthesis pathway was found in the Trichodesmium partitioned genome bins (Fig. 5a). This scaffold contained six protein-coding regions. The first three genes were annotated as phosphoenolpyruvate phosphomu- tase (ppm), phosphonopyruvate decarboxylase ( $p p d)$, and 2aminoethylphosphonate-pyruvate transaminase (2-AEP-TA). These first two genes are most similar to homologs in the UniRef database that belong to the non-heterocystous diazotroph Planktothrix agardhii, a member of the order Oscillatoriales along with Trichodesmium, The 2-AEP-TA is homologous to a gene in a Gammaproteobacterial Beggiatoa sp. The fourth, fifth, and sixth genes in this scaffold were annotated as a methyltransferase, a cytidylyltransferase (both homologs to genes in P. agardhii), and a group 1 glycosyl 
(a)

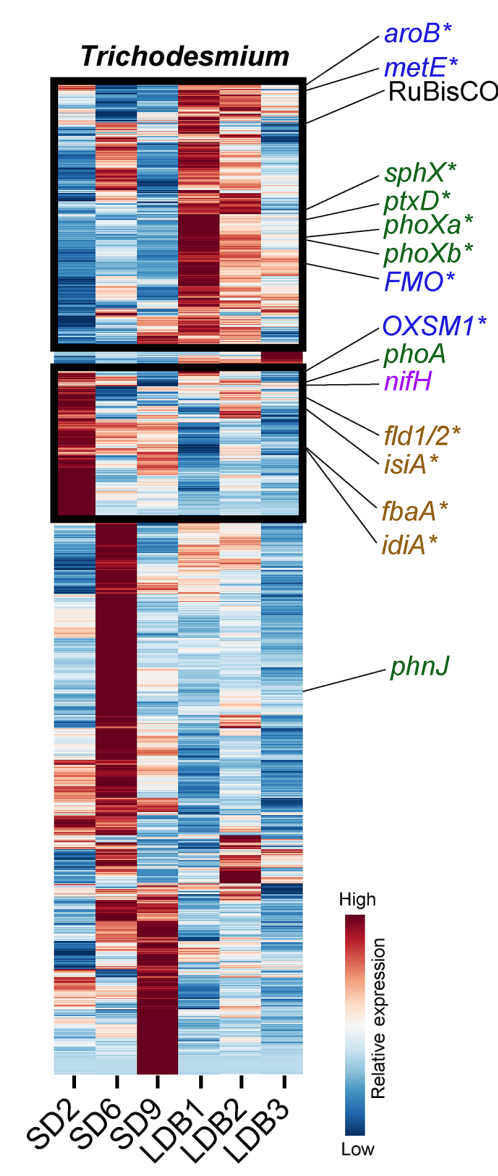

(b)

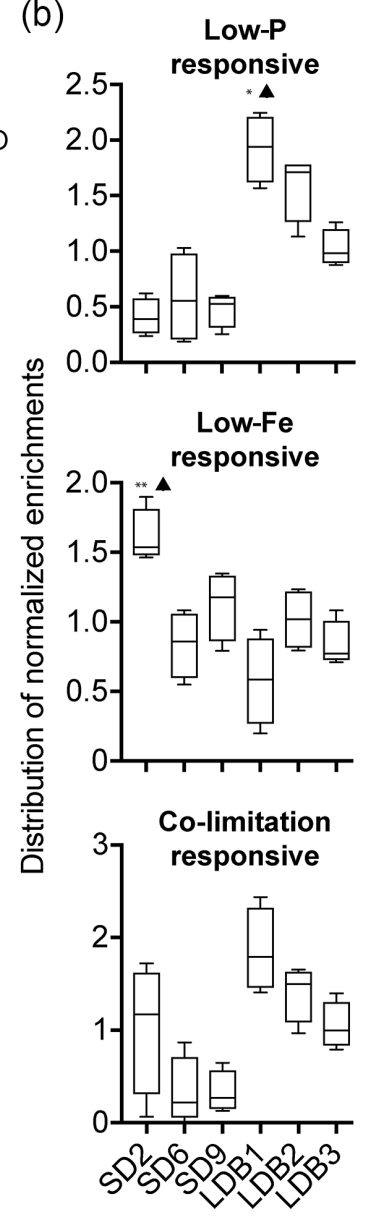

Figure 4. Trichodesmium orthologous group (OG) expression patterns. (a) Hierarchically clustered expression patterns of Trichodesmium OGs with key genes called out. * indicates OGs used in subsequent Kolmogorov-Smirnov tests. Coloured text indicates phosphorus (green), iron (brown), co-limitation (blue), nitrogen (purple), or carbon-fixation-related (black) OGs. (b) Distribution of expression patterns in OG sets known to be significantly responsive in Trichodesmium to low-phosphorus (P), low-iron (Fe), and $\mathrm{P} / \mathrm{Fe}$ co-limiting conditions. Distributions for each set at each station were compared to the average distribution across all six stations using Kolmogorov-Smirnov tests to examine the null hypothesis that the expression of gene sets at a given station did not deviate significantly from the average expression of that set across the transect. Whiskers show the normalized enrichment level for the least and most enriched OG in that set. Boxes denote the upper and lower 25th percentiles, while the line indicates the median enrichment expression value. Asterisks indicate significance: ${ }^{*} p<0.05$, ** $p<0.005$. Black triangles denote whether significant stations were increased or decreased relative to the mean.

transferase (homologous to a gene from a Tolypothrix sp., a freshwater cyanobacterium in the order Nostocales).

In order to verify genome binning of the ppm-containing scaffold into the Trichodesmium fraction, reassembly was attempted to lengthen this scaffold. This effort extended the
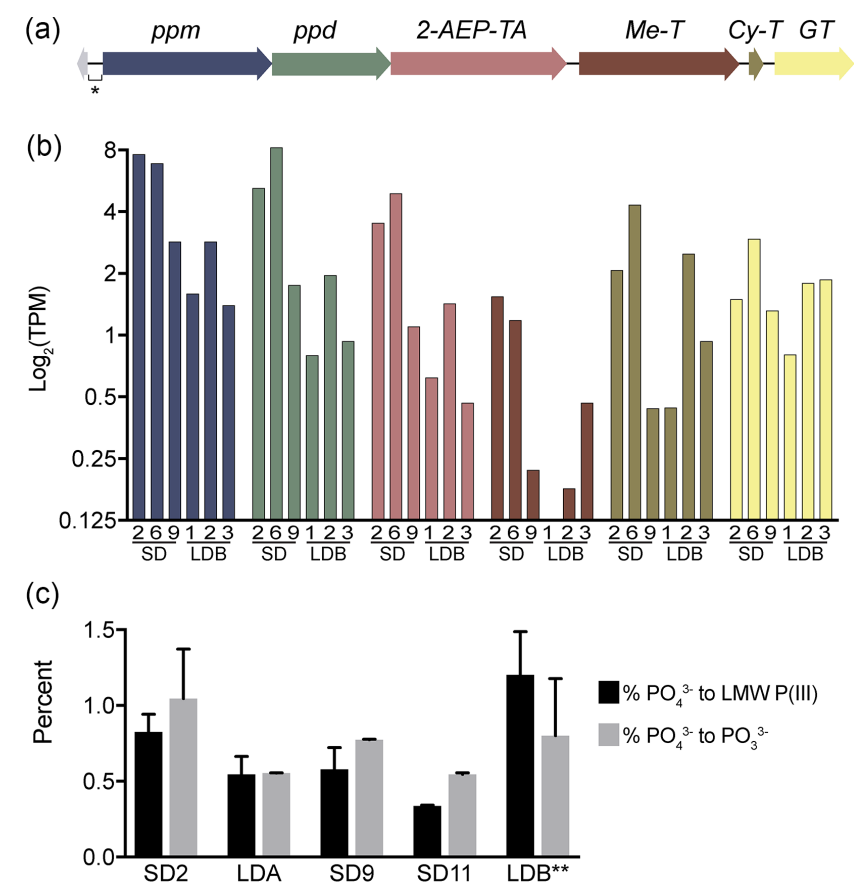

Figure 5. Annotations, topology, and expression levels of a scaffold containing a phosphonate biosynthesis cassette recovered from a Trichodesmium-identified metagenome bin. (a) Gene organization and annotations across the scaffold where arrows represent direction of transcription. ${ }^{*}$ denotes a region with $95 \%$ homology to a non-coding region of the T. erythraeum IMS101 genome. (b) Normalized expression (transcripts per million, TPM) of each OG on this ppm-containing scaffold at each short-duration (SD) or longduration (LDB) station sampled. Column colours match those of the top panel (a). (c) Percentage of total radio-labelled phosphate taken up by Trichodesmium colonies and reduced into low-molecularweight (LMW) phosphonate compounds (including methylphosphonate, phosphonoacetylaldehyde, and 2-aminoethylphosphonate) and phosphite. Error bars denote standard deviation. Abbreviations: ppm is phosphoenolpyruvate phosphomutase; ppd is phosphonopyruvate decarboxylase; $2-A E P$-TA is 2-aminoethylphosphonatepyruvate transaminase; $M e-T$ is SAM-dependent methyltransferase; $C y-T$ is cytidylyltransferase; $G T$ is group 1 glycosyltransferase. ** LDB values represent an average of three measurements obtained during sampling at this long-duration station.

length of the scaffold upstream of the ppm cassette and resulted in the addition of $44 \mathrm{bp}$ to the $5^{\prime}$ end with $95 \%$ homology to a non-coding region in the T. erythraeum IMS101 genome, as well as a protein-coding gene fragment with no known annotation (Fig. 5a; sequence included in Supplement Table 4). Metagenomic reads mapped to this scaffold showed extensive coverage of this IMS101 region as well as mate pairs connecting it to genes downstream in the ppmcontaining cassette (Supplement Fig. 3).

Comparison of the putative Trichodesmium ppm gene's amino acid sequence against experimentally verified phosphonate-bond-forming enzymes in other organisms 
showed high sequence identity (Supplement Fig. 4). Across the length of the peptide sequence, the Trichodesmium Ppm was $72 \%$ and $66 \%$ similar to sequences from the freshwater cyanobacteria Planktothrix sp., and Moorea producens, $65 \%$ similar to those of the freshwater ciliate Tetrahymena, $63 \%$ similar to those of the blue mussel Mytilus edulis, and $35 \%$ similar to those of a bacterium in the Streptomyces genus. Furthermore, closer inspection of the sequences of all organisms showed $100 \%$ identity across residues involved in cofactor and substrate interactions, as well as strong conservation across other key residues involved in the enzyme's tertiary structure as determined by crystal structure analysis and comparison with similar enzymes (Supplement Fig. 4) (Chen et al., 2006). Phylogenetic analysis of Trichodesmium Ppm placed it in a phylogenetic branch along with sequences from other $\mathrm{N}_{2}$-fixing freshwater cyanobacteria (Supplement Fig. 5).

A metagenome derived from Trichodesmium consortia in the western tropical North Atlantic (Frischkorn et al., 2017) was also rescreened for proteins with homology to the Trichodesmium Ppm sequence from this data set. Five homologous sequences were recovered from this North Atlantic metagenome, with two proteins falling in the branch of verified phosphonate-producing Ppm proteins. One protein was located on a branch adjacent to the Trichodesmium Ppm sequences recovered from this South Pacific data set (Supplement Fig. 5). With the exception of the closely related North Atlantic sequence adjacent to the Ppm sequence recovered from this data set, the other similar proteins from the South Pacific and North Atlantic consortia did not exhibit amino acid identity at the key conserved residues determined from crystal structure analysis (Chen et al., 2006).

The T. erythraeum IMS101 genome was also screened for homologs to the Ppm protein recovered here, but no sequences were detected with conserved amino acid identity across important conserved residues. Furthermore, another enzyme responsible for biosynthesis of methylphosphonate, $\mathrm{MpnS}$, was not detected in proteins from the Trichodesmium or microbiome fractions.

All six genes in this scaffold recruited reads after metatranscriptome mapping of each sample, indicating that all genes in the phosphonate biosynthesis cassette were expressed at each station, with the exception of the methyltransferase, which recruited no reads from LDB1 (Fig. 5b). Relative expression of ppm at the three SD stations and the average expression across the three LDB samples was significantly positively correlated with surface water column average abundance $(\sim 5-25 \mathrm{~m})$ of Clade III Trichodesmium ( $R=0.99, p=0.006$, Pearson correlation). Furthermore, the concentration of DIP $(10 \mathrm{~m})$ was positively correlated with both Clade III abundance $(R=0.99, p=0.009$, Pearson correlation) and expression of $p p m(R=0.97, p=0.03$, Pearson correlation). There was no significant correlation between ppm relative expression and Clade I abundance $(p=0.1)$, or between DIP concentration and Clade I abun- dance ( $p=0.13$ ). Coincident with expression of phosphonate biosynthesis genes at all stations sampled, phosphate reduction by Trichodesmium colonies was also detected in each sample analysed (Fig. 5c). At the five stations tested, approximately $2 \%$ of the radio-labelled phosphate taken up by colonies was reduced to either a LMW phosphonate compound (methylphosphonate, phosphonoacetylaldehyde, or 2-aminoethylphosphonate) or phosphite $\left(\mathrm{PO}_{3}^{3-}\right)$ (Fig. 5c). Coincident with phosphonate production, both Trichodesmium and the microbiome possessed and expressed markers for reduced-phosphorus metabolism, including the phosphonate (C-P) lyase phnJ (Tery_5000 in the T. erythraeum IMS101 genome) and ptxD (Tery_0368 in the $T$. erythraeum IMS101 genome), a gene identified as phosphite dehydrogenase that is implicated in oxidation of phosphite to phosphate (Polyviou et al., 2015).

\section{Discussion}

\subsection{Trichodesmium distributions in the oligotrophic WTSP}

The WTSP is considered to be among the most oligotrophic environments in the global ocean due to low concentrations of critical resources like nitrogen, phosphorus, and iron, coupled with intense stratification that prevents upwelling of remineralized nutrients (Moutin et al., 2008). In spite of chronically depleted resources, a diverse assemblage of freeliving and symbiotic diazotrophs thrive in this region (Stenegren et al., 2017). In the WTSP, Trichodesmium is typically abundant, and the Trichodesmium distribution determined here by clade-specific qPCR agreed with previous analyses along this transect using genus-specific qPCR that showed high abundance in the west, decreasing sharply at the transition into the gyre (Stenegren et al., 2017). The absolute value of Trichodesmium cells estimated here must be interpreted with some caution, as cultures and field samples of Trichodesmium are known to exhibit polyploidy (Sargent et al., 2016). However, the counts presented here are tabulated using a standard curve generated from cell counts of cultures of Clade I and Clade III (Rouco et al., 2014, 2016a), which would yield $\mathrm{C}_{\mathrm{T}}$ values that take into account polyploidy, unlike gene standard approaches. Regardless, the consistent trends in relative abundance observed here and with other methods (Stenegren et al., 2017) suggest that the observed patterns are robust and that the level of polyploidy does not likely vary drastically in Trichodesmium populations across the WTSP.

In general, the relative abundance of Trichodesmium was low at the easternmost stations (SD14 and 15) sampled along this transect despite high DIP concentrations detected in this region. This could be due to the low and homogeneous iron concentrations throughout the entire 0 to $500 \mathrm{~m}$ profile $(0.1$ $0.3 \mathrm{nM} \mathrm{DFe}$, Guieu et al., 2018) at these eastern stations, 
limiting growth. This is corroborated by the fact that rates of water column $\mathrm{N}_{2}$ fixation were lowest in the easternmost stations along this transect (Bock et al., 2018; Bonnet et al., 2018). Further, Trichodesmium distribution and overall rates of $\mathrm{N}_{2}$ fixation in the water column were positively correlated with iron (Bonnet et al., 2018). The likely source of this iron was from shallow hydrothermal vents west of the Tonga arc ( $\sim 175^{\circ} \mathrm{W}$, near SD11) (Guieu et al., 2018). Trichodesmium biomass was too low to evaluate gene expression patterns for the easternmost stations, but regardless, these data are consistent with the importance of iron concentration as a driver of Trichodesmium distribution and activities in the WTSP. In addition to iron, phosphorus also likely exerts a strong influence over Trichodesmium in the WTSP. The surface water concentration of DIP measured along this transect was low in the context of the global ocean (Sohm et al., 2011 and references therein) and measured phosphate turnover times in the water column at some stations on the order of hours indicated there was intense competition for phosphate (Van Mooy et al., 2009). The WTSP is poorly sampled relative to other oligotrophic ocean basins (Bonnet et al., 2018; Luo et al., 2012), and little is definitively known about the canonical resource controls that characterize this environment over prolonged time periods (Sohm et al., 2011). Herein, the Trichodesmium distributions were consistent with the potential roles of both iron and phosphorus in driving the physiological ecology of this genus in the WTSP.

\subsection{Expression of metabolic potential in Trichodesmium and its microbiome}

Trichodesmium does not exist in isolation, as filaments and colonies are associated with an assemblage of epibiotic microorganisms that co-occur ubiquitously in the environment (Lee et al., 2017; Rouco et al., 2016b) and contribute a large amount of metabolic potential that could underpin success in oligotrophic, low-nutrient environments (Frischkorn et al., 2017). At the broadest functional level, the microbiome contained approximately 10 times the unique KEGG functions found within the Trichodesmium fraction of the WSTP, and these functions were largely consistent with those observed previously in the western North Atlantic (Frischkorn et al., 2017). The presence of unique microbiome transporter functions, especially those related to the transport of phosphate and metals including iron, reflect the importance of these resources within the colony microenvironment, which is likely depleted in these key resources. The enrichment of microbiome functions related to the transport and subsequent metabolism of sugars, carbohydrates, and lipids could reflect the transfer of fixed carbon from host to microbiome, as the genes encoding these functions are known to oscillate over day-night cycles in lockstep with Trichodesmium photosynthesis and carbon fixation genes (Frischkorn et al., 2018). These oscillations may support respiration processes that help maintain an environment favourable for $\mathrm{N}_{2}$ fixation, and the functional enrichment observed here could underpin interactions within the holobiont that help maintain $\mathrm{N}_{2}$ fixation in the WTSP, despite the scarcity of resources.

In addition to distinct functions in the metagenome, the expression of broad functional categories varied for Trichodesmium and the microbiome. Expression of OGs that belonged to carbohydrate metabolism and nucleotide and amino acid metabolism KEGG modules was elevated at the three SD stations sampled, relative to the 3 days of samples obtained from LDB. Arrival at this long-duration station coincided with the decline of a phytoplankton bloom that had been at this location for approximately 2 months (De Verneil et al., 2017). Coincident with this decline in sea surface chlorophyll $a$, heterotrophic bacterial populations at LDB differed from other stations both taxonomically and in their response during experimental incubation with increased dissolved organic compounds from copepods (Valdés et al., 2018). In Trichodesmium, the decreased relative expression at LDB samples in functions related to carbon fixation, DNA and RNA replication, and a suite of amino acid metabolic functions that require nitrogen relative to the SD stations suggest shifts away from these energy-intensive and cell-division processes with bloom demise. Similarly, in the microbiome, decreased relative expression of functional categories over the course of sampling at LDB could reflect shifts in physiology away from reliance on Trichodesmium or changes in community structure away from common colonizers of Trichodesmium to opportunistic or saprophytic species, For example, in the coral reef system, pulses of organic carbon similar to what could be released during a declining phytoplankton bloom led to activity shifts in associated bacterioplankton, including the increased expression of virulence factors (Cárdenas et al., 2018). Taken together, these data continue to reinforce that the microbiome both possesses and expresses unique metabolic potential relative to Trichodesmium alone, and as such, could play an important role in the physiological ecology of this important diazotroph.

\subsection{Expression of resource-related signals in Trichodesmium}

The expression of genes that lead to changes in activities like nitrogen fixation (nifH) or resource acquisition (e.g. phoX) can be used to assess the physiology of Trichodesmium in situ. Genes responsive to low-phosphorus and -iron conditions are particularly well studied in Trichodesmium (e.g. Chappell et al., 2012; Chappell and Webb, 2010; Dyhrman et al., 2006; Orchard et al., 2009; Snow et al., 2015) and a recent culture study assessed the physiological response of Trichodesmium to coupled low-phosphorus and low-iron conditions, yielding a set of genes with significantly elevated expression under co-limitation conditions (Walworth et al., 2017). Expression of many of these marker genes is heavily repressed in cultures grown under replete conditions (Chap- 
pell and Webb, 2010; Orchard et al., 2009) or in field samples with relatively high concentrations of resources like iron (e.g. Chappell et al., 2012). Expression of these resourceresponsive OG sets was detected in Trichodesmium across all samples, indicating that there was intense scavenging of phosphorus and iron, consistent with the low levels of these resources at stations analysed for gene expression.

The expression of P-responsive OGs related to phosphate uptake $(\operatorname{sph} X)$, phosphoester hydrolysis $(p h o X)$, and the metabolism of phosphite $(p t x D)$ tracked together, with RuBisCO, and were significantly enriched at LDB 1 . This pattern may indicate increased $P$ stress at LDB 1 relative to other stations on the transect and may be an indicator of shifts in Trichodesmium physiology associated with modulating carbon fixation and or the declining bloom in this region (De Verneil et al., 2017). For example, increased expression of $p t x D$ may indicate increased metabolism of phosphite. Notably, the expression of this low-P responsive set, which included OGs related to phosphate uptake $(s p h X)$, was significantly enriched at LDB 1 , where the phosphate turnover time was among the lowest observed. Although phnJ has been shown to be regulated by phosphorus concentration in culture studies (Dyhrman et al., 2006), the phnJ OG here deviated from the expression pattern of the other P-responsive genes like phoX. As a result, there may be some variability in Trichodesmium processing of phosphoesters and phosphonates over these stations. Regardless, the expression of $p h o X, p t x D$, and phnJ OGs underscores the importance of organic phosphorus compounds, and phosphite in supporting Trichodesmium growth across the WTSP.

The OGs in the low-Fe responsive set were also detected at all stations, consistent with the sub-nanomolar concentrations of iron observed across the transect. This set was significantly enriched at SD2, where iron concentration was roughly half that of LDB. Although a larger data set would be needed to fully resolve patterns of iron stress, these data are suggestive of an increase in Trichodesmium iron stress at SD2 compared to the other stations. Given that rates of $\mathrm{N}_{2}$ fixation in the water column were positively correlated with iron (Bonnet et al., 2018), and Trichodesmium was commonly a dominant diazotroph with the high cell-specific $\mathrm{N}_{2}$ fixation activity (Stenegren et al., 2017; Bonnet et al., 2018), these patterns of gene expression are consistent with iron control of Trichodesmium $\mathrm{N}_{2}$ fixation at SD2. Strikingly, expression of the alkaline phosphatase phoA, and the nitrogenase subunit nifH had similar expression patterns to this low-Fe responsive set. Nitrogenase requires iron and its expression in Trichodesmium is closely synchronized with iron processes (Frischkorn et al., 2018). Conversely, the enzyme PhoA does not require iron and instead uses a zincmagnesium cofactor, as opposed to PhoX, which has an ironcalcium cofactor (Luo et al., 2009; Yong et al., 2014). In lowiron environments, Trichodesmium phoA is known to show an enriched expression relative to that of phoX (Rouco et al., 2018), a strategy that could free up iron for use in photo- synthetic or nitrogen fixation enzymes. Collectively, these results suggest there is intense scavenging of iron by Trichodesmium in the WSTP, and in this and other environments where multiple resources can be low or co-limiting, cofactors like iron could play a role in the phosphorus acquisition strategies employed by Trichodesmium.

The OGs in the co-limitation responsive set were detected in all samples. The expression patterns of these co-limitation responsive OGs clustered among both the low-P and lowFe sets, and there were no significant patterns of enrichment between stations. The lack of significant enrichment in the co-limitation set is consistent with the fact that the low-P and low-Fe responsive sets were not simultaneously enriched at the same station. Broadly, however, the expression patterns between low-P and co-limitation sets were more similar to each other than shown for the low-Fe responsive set, suggesting that across these samples phosphorus was a driver of expression of co-limitation OGs. More field observations over a greater range in iron and phosphorus might further resolve these putative co-limitation signals, which have not been previously tracked in field populations. Collectively, the OGs expressed across this WTSP transect are suggestive of the importance of both iron and phosphorus in driving Trichodesmium physiological ecology in this region. These results provide physiological and metabolic context to the abundance and activity of Trichodesmium observed in surface waters across the OUTPACE transect. Together with studies of Trichodesmium in regions with contrasting geochemical characteristics, like the North Atlantic and North Pacific (Rouco et al., 2018), these observations of Trichodesmium from the undersampled WTSP enhance understanding of the constraints on this geochemically important diazotroph across diverse oligotrophic environments.

\subsection{Phosphonate biosynthesis by Trichodesmium in the WTSP}

Phosphate exists in vanishingly low concentrations in the oligotrophic surface ocean and the activity of diazotrophs increases the demand for phosphorus by relieving nitrogen stress - a process that is enhanced by periodic increases in iron availability (Moutin et al., 2005). In low-phosphate environments, marine microbes like Trichodesmium can hydrolyse phosphate from organically bound compounds like phosphoesters and phosphonates, the concentrations of which far surpass phosphate in the oligotrophic ocean (Dyhrman et al., 2007). The production and hydrolysis of reduced compounds like phosphonates are of particular interest because the hydrolysis of methylphosphonate has the potential to release methane, a potent greenhouse gas (Karl et al., 2008; Repeta et al., 2016). Previous studies showing biosynthesis of phosphonates by certain Trichodesmium isolates (Dyhrman et al., 2009) as well as rapid phosphate reduction to phosphonate and phosphite and release by Trichodesmium colonies in the environment (Van Mooy et al., 2015) implicate this dia- 
zotroph as an important player in phosphonate biogeochemistry, yet the molecular mechanisms underlying phosphonate biosynthesis are poorly understood for this genus.

A Trichodesmium scaffold containing the full set of genes necessary to synthesize phosphonate compounds was recovered from metagenomes assembled from this WTSP transect. The Trichodesmium origin of this scaffold is supported by tetranucleotide frequency and metagenomic read mapping coverage, as well as the presence of a stretch of noncoding DNA with homology to the T. erythraeum IMS101 genome. Furthermore, the protein in this scaffold identified as phosphoenolpyruvate phosphomutase (Ppm), the enzyme that carries out the formation of a carbon-phosphorus bond using phosphoenolpyruvate as a substrate (McGrath et al., 2013), was phylogenetically most similar to Ppm sequences from cyanobacteria like Planktothrix that are closely related to Trichodesmium. The phylogenetic distance between the Trichodesmium Ppm and those of heterotrophic bacteria further support that this scaffold was recovered from a Trichodesmium genome and not from a member of the microbiome.

The molecular machinery necessary to synthesize phosphonates is evolutionarily conserved and the biosynthesis of phosphonoacetaldehyde is the starting point from which a diverse suite of organic phosphonate compounds can be produced (McGrath et al., 2013). Based on the genes in this Trichodesmium scaffold, synthesis begins with the formation of the carbon-phosphorus bond after molecular rearrangement of phosphoenolpyruvate to phosphonopyruvate, catalysed by Ppm. Next, phosphonopyruvate decarboxylase (Ppd), the protein encoded by the following gene in the cassette, likely performs the irreversible conversion of phosphonopyruvate to phosphonoacetaldehyde which prevents reversion to the ester bond structure. Finally, the presence of the gene for 2-aminoethylphosphonic acid pyruvatetransaminase (2-AEP-TA) suggests that phosphonoacetaldehyde is further converted to 2-aminoethylphosphonate (2AEP), the organophosphonate that occurs most commonly in the environment (McGrath et al., 2013). The mpnS gene mediates the production of methylphosphonate downstream of ppm in the marine microbes where it has been detected (Metcalf et al., 2012). There was no evidence of $m p n S$ in Trichodesmium or the microbiome, but Trichodesmiumderived phosphonates could potentially be further modified to methylphosphonate by organisms not associated with colonies.

The ppm gene can be found in approximately $7 \%$ of microbial genome equivalents recovered from the Global Ocean Survey, and of these ppm-containing genomes, $20.6 \%$ are estimated to be cyanobacterial in origin (Yu et al., 2013). A protein with homology to $\mathrm{Ppm}$ was previously detected and attributed to Trichodesmium in metagenomic samples from the western North Atlantic (Frischkorn et al., 2017), though this gene was not found to be part of a 2-AEP synthesis cassette. OGs derived from genes on the ppm-containing
Trichodesmium scaffold identified here recruited metatranscriptomic reads from each sample sequenced, suggesting active use of these enzymes across the transect. Furthermore, reduced-phosphonate compounds (which would include 2AEP) were produced from radio-labelled phosphate taken up by Trichodesmium colonies at each station analysed. Together, these results clearly illustrate a pathway by which Trichodesmium synthesizes phosphonates and that this pathway is active in the WTSP and likely other environments like the western North Atlantic, where high rates of phosphate reduction in Trichodesmium colonies have also been measured (Van Mooy et al., 2015).

The relative expression of the ppm OG across the transect was significantly correlated with the abundance of Trichodesmium Clade III, Although this is consistent with the detection of phosphonates in cultured T. erythraeum isolates from Clade III (Dyhrman et al., 2009), no clear homologs of ppm have been found in the T. erythraeum IMS101 genome assembly. At this juncture, this may be attributable to an incomplete genome, or the pathway could be mediated with a different mechanism, and more work would be required to screen Trichodesmium isolates for ppm. Regardless, these field data are consistent with culture studies that suggest that phosphonate biosynthesis may be variably present in different Trichodesmium clades or species (Dyhrman et al., 2009). Across this WTSP transect, Clade III accounted for up to $47.5 \%$ of the total Trichodesmium population in some locations and in general composed nearly $20 \%$ of the population on average from station to station. This percentage of Clade III is considerably higher than that observed in the western North Atlantic (Rouco et al., 2014) and higher than in the North Pacific subtropical gyre (Rouco et al., 2016a). If phosphonate biosynthesis is consistently a unique feature of Clade III, then Trichodesmium-mediated phosphonate production could be higher in the South Pacific than other ocean basins. Furthermore, models project that future ocean conditions will select for the dominance of $T$. erythraeum (Clade III) over that of Clade I species like T. thiebautii, which are most abundant in the present ocean (Hutchins et al., 2013). Such an expansion of T. erythraeum could lead to a subsequent increase in phosphonate biosynthesis and an increase in the availability of these compounds in the water column.

The production of a recalcitrant form of phosphorus and its potential release into the oligotrophic environment could have important consequences for microbial communities. Phosphonates are a critical source of phosphorus in the oligotrophic ocean, and the ability to utilize this resource could influence microbial ecology in low-nutrient environments. Across this transect, both Trichodesmium and their microbiome contained and expressed OGs related to phosphonate catabolism, including the marker of the C-P lyase enzyme complex, phnJ. Trichodesmium and microbiome phnJ genes have also been detected and expressed in Trichodesmium communities from the chronically low-phosphate western 
North Atlantic ocean as well as the North Pacific subtropical gyre (Dyhrman et al., 2006; Frischkorn et al., 2017, 2018). In addition to the production and hydrolysis of phosphonate compounds, we also detected evidence of the use of other forms of reduced phosphorus. The ptxD gene, which is responsible for the oxidation of phosphite, another reduced phosphorus compound (Polyviou et al., 2015), was also present and expressed by Trichodesmium and the microbiome at all stations sampled. This finding suggests active transformation and exchange of reduced phosphorus compounds between consortia members. In the low-phosphorus western North Atlantic, up to $16 \%$ of the phosphate taken up by Trichodesmium colonies has been shown to be reduced and subsequently released from cells, an amount of phosphorus cycling that rivals the amount of input to marine systems from allochthonous or atmospheric sources (Van Mooy et al., 2015). The evidence of utilization of these traits across additional geochemical environments, like in the WTSP, and the large quantities of phosphorus they recycle suggests that phosphonate cycling comprises an integral facet of the Trichodesmium holobiont's physiology, yet the reasons behind this cycling remain enigmatic. Not all microbes can metabolize phosphonates (Villarreal-Chiu, 2012); therefore it could also be plausible that formation of such compounds creates a cryptic phosphorus pool that would in part restrict access to this critical nutrient by other microbes. Uptake and reduction to a more recalcitrant form as a mechanism of luxury storage exclusive to members of the Trichodesmium holobiont is supported by the significant positive correlation between expression of ppm and DIP concentration. In short, exchange of these compounds within the Trichodesmium holobiont, especially if through a cryptic pool, could help to support $\mathrm{N}_{2}$ fixation in Trichodesmium by modulating access to bioavailable phosphorus in the oligotrophic WTSP (Van Mooy et al., 2015).

Marine $\mathrm{N}_{2}$ fixation is expected to increase in future oceans that are predicted to have higher temperatures and $\mathrm{CO}_{2}$ concentration (Hutchins et al., 2007), and Trichodesmium cultures incubated in high $\mathrm{CO}_{2}$, conditions exhibited irreversibly increased rates of $\mathrm{N}_{2}$ fixation (Hutchins et al., 2015). In these conditions, cycling of phosphonate compounds that are not accessible to the full microbial community could support enhanced $\mathrm{N}_{2}$ fixation if enough iron is available, the release of new nitrogen into the water column and subsequently fuel primary production. In future studies it will be important to assess how future ocean conditions will alter the clade distribution of Trichodesmium in the environment, as this could play a role in determining the potential flux of phosphonate compounds from colonies to the water column.

\section{Conclusion}

Marine microbes interact and alter the environment through abiotic transformations as well as through biotic interactions with one another and across trophic levels, and these processes work in tandem to influence global biogeochemical cycles. Understanding these processes in situ is of paramount importance to forecasting the ocean's role in the future climate, yet challenges persist with sampling remote locations and filling knowledge gaps surrounding the ecology and physiology of key species. The OUTPACE research expedition afforded a unique opportunity to investigate communities of the keystone $\mathrm{N}_{2}$ fixer Trichodesmium and their microbiome in the undersampled South Pacific. Metagenomic and metatranscriptomic data showed a majority of unique physiological functions within the microbiome, many of which were expressed in situ, and these functions may be important to Trichodesmium physiological ecology in this environment. Patterns of OG expression in low-Fe responsive, low-P responsive, and co-limitation sets suggested that iron and phosphorus are highly scavenged and that Trichodesmium variably experienced changes in these resources, which could modulate growth and $\mathrm{N}_{2}$ fixation in situ. A Trichodesmium gene cassette for the biosynthesis of the phosphonates, its expression, and corresponding phosphate reduction rate measurements suggested that Trichodesmium is producing reduced phosphate in the WTSP. This finding expands the environments where phosphate reduction has been detected and confirms the role of Trichodesmium in this poorly understood aspect of phosphorus biogeochemistry. Collectively, these data underscore the importance of iron and phosphorus, and the microbiome, in jointly driving the physiological ecology of this key diazotroph in the WTSP.

Data availability. Sequence data is available on the NCBI SRA under accession number PRJNA435427.

Other OUTPACE data products are available at http://www. obs-vlfr.fr/proof/php/outpace/outpace.php, last access: 24 September 2018 .

\section{The Supplement related to this article is available online at https://doi.org/10.5194/bg-15-5761-2018-supplement.}

Author contributions. KRF, BASVM, and STD conceived of the study and its design. KRF, AK, CG, JL, MR, AESE, and BASVM conducted the experiments and analyzed the data. KRF and STD wrote the paper with critical input from all co-authors.

Competing interests. The authors declare they have no conflicts of interest.

Special issue statement. This article is part of the special issue "Interactions between planktonic organisms and biogeochemical cycles across trophic and $\mathrm{N}_{2}$ fixation gradients in the western tropical South Pacific Ocean: a multidisciplinary approach (OUTPACE experiment)". It is not associated with a conference. 
Acknowledgements. This is a contribution to the OUTPACE (Oligotrophy to UlTra-oligotrophy PACific Experiment) project, which was funded by the French national research agency (ANR-14-CE01-0007-01), the LEFE-CyBER program (CNRS-8 INSU), the GOPS program (IRD) and the CNES (BC T23, ZBC 4500048836). The authors thank Thierry Moutin and Sophie Bonnet for leading the OUTPACE expedition and for the invitation to participate. The authors also thank the OUTPACE science party and the captain and crew of the RV L'Atalante for their assistance and camaraderie while underway. Special thanks to Andrea Caputo and Marcus Stenegren of Stockholm University for assistance while at sea. The authors also acknowledge the Carbonate cluster of the National Center for Genome Analysis Support, and Carrie Ganote in particular, for bioinformatics assistance. Grants from the National Science Foundation to STD (OCE-1332912) and BASVM (OCE-1536346 and OCE-1332898) supported this research. KRF is partially supported by a National Science Foundation Graduate Research Fellowship (DGE-16-44869). This research was also funded by the Simons Foundation's Simons Collaboration on Ocean Processes and Ecology (SCOPE) (SCOPE award ID 329108 to STD and BVM) and is a contribution of SCOPE.

Edited by: Thierry Moutin

Reviewed by: Ulrike Pfreundt and one anonymous referee

\section{References}

Bergman, B., Sandh, G., Lin, S., Larsson, J., and Carpenter, E. J.: Trichodesmium-a widespread marine cyanobacterium with unusual nitrogen fixation properties., FEMS Microbiol. Rev., 37, 286-302, https://doi.org/10.1111/j.1574-6976.2012.00352.x, 2013.

Blain, S., Bonnet, S., and Guieu, C.: Dissolved iron distribution in the tropical and sub tropical South Eastern Pacific, Biogeosciences, 5, 269-280, https://doi.org/10.5194/bg-5-2692008, 2008.

Bock, N., Van Wambeke, F., Dion, M., and Duhamel, S.: Microbial community structure in the western tropical South Pacific, Biogeosciences, 15, 3909-3925, https://doi.org/10.5194/bg-153909-2018, 2018.

Bonnet, S., Caffin, M., Berthelot, H., and Moutin, T.: Hot spot of $\mathrm{N}_{2}$ fixation in the western tropical South Pacific pleads for a spatial decoupling between $\mathrm{N}_{2}$ fixation and denitrification, P. Natl. Acad. Sci. USA, 114, E2800-E2801, https://doi.org/10.1073/pnas.1619514114, 2017.

Bonnet, S., Caffin, M., Berthelot, H., Grosso, O., Benavides, M., Helias-Nunige, S., Guieu, C., Stenegren, M., and Foster, R. A.: In-depth characterization of diazotroph activity across the western tropical South Pacific hotspot of $\mathrm{N}_{2}$ fixation (OUTPACE cruise), Biogeosciences, 15, 4215-4232, https://doi.org/10.5194/bg-15-4215-2018, 2018.

Brown, C. T., Sheneman, L. S., Camille, C. M., Rosenthal, J. H., and Adina, C.: khmer-protocols documentation, available at: https://khmer-protocols.readthedocs.io/en/ latest/mrnaseq/index.html (last access: 17 September 2018), 2013.

Buchfink, B., Xie, C., and Huson, D. H.: Fast and sensitive protein alignment using DIAMOND, Nat. Methods, 12, 59-60, https://doi.org/10.1038/nmeth.3176, 2015.
Caffin, M., Moutin, T., Foster, R. A., Bouruet-Aubertot, P., Doglioli, A. M., Berthelot, H., Guieu, C., Grosso, O., Helias-Nunige, S., Leblond, N., Gimenez, A., Petrenko, A. A., de Verneil, A., and Bonnet, S.: $\mathrm{N}_{2}$ fixation as a dominant new $\mathrm{N}$ source in the western tropical South Pacific Ocean (OUTPACE cruise), Biogeosciences, 15, 2565-2585, https://doi.org/10.5194/bg-152565-2018, 2018a.

Caffin, M., Berthelot, H., Cornet-Barthaux, V., Barani, A., and Bonnet, S.: Transfer of diazotroph-derived nitrogen to the planktonic food web across gradients of $\mathrm{N}_{2}$ fixation activity and diversity in the western tropical South Pacific Ocean, Biogeosciences, 15, 3795-3810, https://doi.org/10.5194/bg-15-3795-2018, 2018b.

Capone, D. G., Zehr, J. P., Paerl, H. W., Bergman, B., and Carpenter, E. J.: Trichodesmium, a globally significant marine cyanobacterium, Science, 276, 1221-1229, 1997.

Cárdenas, A., Neave, M. J., Haroon, M. F., Pogoreutz, C., Rädecker, N., Wild, C., Gärdes, A., and Voolstra, C. R.: Excess labile carbon promotes the expression of virulence factors in coral reef bacterioplankton, ISME J., 12, 59-76. https://doi.org/10.1038/ismej.2017.142, 2018.

Chappell, P. D. and Webb, E. A.: A molecular assessment of the iron stress response in the two phylogenetic clades of Trichodesmium, Environ. Microbiol., 12, 13-27, https://doi.org/10.1111/j.14622920.2009.02026.x, 2010.

Chappell, P. D., Moffett, J. W., Hynes, A. M., and Webb, E. A.: Molecular evidence of iron limitation and availability in the global diazotroph Trichodesmium, ISME J., 6, 1728-1739, https://doi.org/10.1038/ismej.2012.13, 2012.

Chen, C. C. H., Han, Y., Niu, W., Kulakova, A. N., Howard, A., Quinn, J. P., Dunaway-Mariano, D., and Herzberg, O.: Structure and kinetics of phosphonopyruvate hydrolase from Voriovorax sp. Pal2: New insight into the divergence of catalysis within the pep mutase/isocitrate lyase superfamily, Biochemistry, 45, 11491-11504, https://doi.org/10.1021/bi0612081, 2006.

De Verneil, A., Rousselet, L., Doglioli, A. M., Petrenko, A. A., and Moutin, T.: The fate of a southwest Pacific bloom: Gauging the impact of submesoscale vs. mesoscale circulation on biological gradients in the subtropics, Biogeosciences, 14, 3471-3486, https://doi.org/10.5194/bg-14-3471-2017, 2017.

Dyhrman, S. T., Chappell, P. D., Haley, S. T., Moffett, J. W., Orchard, E. D., Waterbury, J. B., and Webb, E. A.: Phosphonate utilization by the globally important marine diazotroph Trichodesmium, Nature, 439, 68-71, 2006.

Dyhrman, S. T., Ammerman, J. W., and Van Mooy, B. A. S.: Microbes and the marine phosphorus cycle, Oceanography, 20, 110-116, 2007.

Dyhrman, S. T., Benitez-Nelson, C. R., Orchard, E. D., Haley, S. T., and Pellechia, P. J.: A microbial source of phosphonates in oligotrophic marine systems, Nat. Geosci., 2, 696-699, https://doi.org/10.1038/ngeo639, 2009.

Eddy, S. R.: Multiple alignment using hidden Markov models, Proc. Int. Conf. Intell. Syst. Mol. Biol., 3, 114-120, 7584426, 1995.

Edgar, R. C.: MUSCLE: multiple sequence alignment with high accuracy and high throughput, Nucl. Acids Res., 32, 1792-1797, 2004.

Frischkorn, K. R., Rouco, M., Van Mooy, B., and Dyhrman, S. T.: Epibionts dominate metabolic functional potential of Trichodesmium colonies from the oligotrophic ocean, ISME J., 11, 2090-2101, https://doi.org/10.1038/ismej.2017.74, 2017. 
Frischkorn, K. R., Haley, S. T., and Dyhrman, S. T.: Coordinated gene expression between Trichodesmium and its microbiome over day-night cycles in the North Pacific Subtropical Gyre, ISME J., 12, 997-1007, https://doi.org/10.1038/s41396017-0041-5, 2018.

Guieu, C., Bonnet, S., Petrenko, A., Menkes, C., Chavagnac, V., Desboeufs, K., Maes, C., and Moutin, T.: Iron from a submarine source impacts the productive layer of the Western Tropical South Pacific (WTSP), Sci. Rep., 8, 9075, https://doi.org/10.1038/s41598-018-27407-z, 2018.

Hmelo, L., Van Mooy, B., and Mincer, T.: Characterization of bacterial epibionts on the cyanobacterium Trichodesmium, Aquat. Microb. Ecol., 67, 1-14, https://doi.org/10.3354/ame01571, 2012.

Huson, D. H., El Hadidi, M., Ruscheweyh, H., Huson, D. H., and Meta, S.: Improved metagenome analysis using MEGAN5, available at: http://ab.inf.uni-tuebingen.de/software/megan5/ (last access: 17 September 2018), 2013.

Hutchins, D. A., Fu, F.-X., Zhang, Y., Warner, M. E., Feng, Y., Portune, K., Bernhardt, P. W., and Mulholland, M. R.: $\mathrm{CO}_{2}$ control of Trichodesmium $\mathrm{N}_{2}$ fixation, photosynthesis, growth rates, and elemental ratios: Implications for past, present, and future ocean biogeochemistry, Limnol. Oceanogr., 52, 1293-1304, https://doi.org/10.4319/lo.2007.52.4.1293, 2007.

Hutchins, D. A., Fu, F.-X., Webb, E. A., Walworth, N., and Tagliabue, A.: Taxon-specific response of marine nitrogen fixers to elevated carbon dioxide concentrations, Nat. Geosci., 6, 1-6, 2013.

Hutchins, D. A., Walworth, N. G., Webb, E. A., Saito, M. A., Moran, D., McIlvin, M. R., Gale, J., and Fu, F.-X.: Irreversibly increased nitrogen fixation in Trichodesmium experimentally adapted to elevated carbon dioxide, Nat. Commun., 6, 8155, https://doi.org/10.1038/ncomms9155, 2015.

Hyatt, D., Chen, G.-L., Locascio, P. F., Land, M. L., Larimer, F. W., and Hauser, L. J.: Prodigal: prokaryotic gene recognition and translation initiation site identification, BMC Bioinformatics, 11, https://doi.org/10.1186/1471-2105-11-119, 2010.

Karl, D. M., Beversdorf, L., Björkman, K. M., Church, M. J., Martinez, A., and Delong, E. F.: Aerobic production of methane in the sea, Nat. Geosci., 1, 473-478, https://doi.org/10.1038/ngeo234, 2008.

Kearse, M., Moir, R., Wilson, A., Stones-Havas, S., Cheung, M., Sturrock, S., Buxton, S., Cooper, A., Markowitz, S., Duran, C., Thierer, T., Ashton, B., Meintjes, P., and Drummond, A.: Geneious Basic: An integrated and extendable desktop software platform for the organization and analysis of sequence data, Bioinformatics, 28, 1647-1649, https://doi.org/10.1093/bioinformatics/bts199, 2012.

Lee, M. D., Walworth, N. G., Mcparland, E. L., Fu, F., Mincer, T. J., Levine, N. M., Hutchins, D. A., and Webb, E. A.: The Trichodesmium consortium: conserved heterotrophic co-occurrence and genomic signatures of potential interactions, ISME J., 11, 1813-1824, https://doi.org/10.1038/ismej.2017.49, 2017.

Lee, M. D., Webb, E. A., Walworth, N. G., Fu, F., Held, N. A., Saito, M. A., and Hutchins, D. A.: Transcriptional activities of the microbial consortium living with the marine nitrogenfixing cyanobacterium Trichodesmium reveal potential roles in community-level nitrogen cycling, Appl. Environ. Microbiol., 84, 1-16, 2018.

Letunic, I. and Bork, P.: Interactive tree of life (iTOL) v3: an online tool for the display and annotation of phyloge- netic and other trees, Nucleic Acids Res., 44, W242-W245, https://doi.org/10.1093/nar/gkw290, 2016.

Li, B. and Dewey, C. N.: RSEM: accurate transcript quantification from RNA-Seq data with or without a reference genome, BMC Bioinformatics, 12, https://doi.org/10.1186/1471-2105-12323, 2011.

Li, H., Handsaker, B., Wysoker, A., Fennell, T., Ruan, J., Homer, N., Marth, G., Abecasis, G., and Durbin, R.: The Sequence Alignment/Map format and SAMtools, Bioinformatics, 25, 20782079, https://doi.org/10.1093/bioinformatics/btp352, 2009.

Luo, H., Benner, R., Long, R. A., and Hu, J.: Subcellular localization of marine bacterial alkaline phosphatases, P. Natl. Acad. Sci. USA, 106, 21219-21223, https://doi.org/10.1073/pnas.0907586106, 2009.

Luo, Y.-W., Doney, S. C., Anderson, L. A., Benavides, M., BermanFrank, I., Bode, A., Bonnet, S., Boström, K. H., Böttjer, D., Capone, D. G., Carpenter, E. J., Chen, Y. L., Church, M. J., Dore, J. E., Falcón, L. I., Fernández, A., Foster, R. A., Furuya, K., Gómez, F., Gundersen, K., Hynes, A. M., Karl, D. M., Kitajima, S., Langlois, R. J., LaRoche, J., Letelier, R. M., Marañón, E., McGillicuddy Jr., D. J., Moisander, P. H., Moore, C. M., Mouriño-Carballido, B., Mulholland, M. R., Needoba, J. A., Orcutt, K. M., Poulton, A. J., Rahav, E., Raimbault, P., Rees, A. P., Riemann, L., Shiozaki, T., Subramaniam, A., Tyrrell, T., Turk-Kubo, K. A., Varela, M., Villareal, T. A., Webb, E. A., White, A. E., Wu, J., and Zehr, J. P.: Database of diazotrophs in global ocean: abundance, biomass and nitrogen fixation rates, Earth Syst. Sci. Data, 4, 47-73, https://doi.org/10.5194/essd-447-2012, 2012.

McGrath, J. W., Chin, J. P., and Quinn, J. P.: Organophosphonates revealed: new insights into the microbial metabolism of ancient molecules., Nat. Rev. Microbiol., 11, 412-419, https://doi.org/10.1038/nrmicro3011, 2013.

Metcalf, W. W., Griffin, B. M., Cicchillo, R. M., Gao, J., Janga, S. C., Cooke, H. A., Circello, B. T., Evans, B. S., MartensHabbena, W., Stahl, D. A., and van der Donk, W. A.: Synthesis of methylphosphonic acid by marine microbes: A source for methane in the aerobic ocean, Science, 337, 1104-1107, 2012.

Moore, C. M., Mills, M. M., Arrigo, K. R., Berman-Frank, I., Bopp, L., Boyd, P. W., Galbraith, E. D., Geider, R. J., Guieu, C., Jaccard, S. L., Jickells, T. D., La Roche, J., Lenton, T. M., Mahowald, N. M., Marañón, E., Marinov, I., Moore, J. K., Nakatsuka, T., Oschlies, A., Saito, M. A., Thingstad, T. F., Tsuda, A., and Ulloa, O.: Processes and patterns of oceanic nutrient limitation, Nat. Geosci., 6, 701-710, https://doi.org/10.1038/ngeo1765, 2013.

Moutin, T., Van Den Broeck, N., Beker, B., Dupouy, C., Rimmelin, P., and Le Bouteiller, A.: Phosphate availability controls Trichodesmium spp. biomass in the SW Pacific Ocean, Mar. Ecol. Prog. Ser., 297, 15-21, https://doi.org/10.3354/meps297015, 2005.

Moutin, T., Karl, D. M., Duhamel, S., Rimmelin, P., Raimbault, P., Van Mooy, B. A. S., and Claustre, H.: Phosphate availability and the ultimate control of new nitrogen input by nitrogen fixation in the tropical Pacific Ocean, Biogeosciences, 5, 95-109, https://doi.org/10.5194/bg-5-95-2008, 2008.

Moutin, T., Michelangelo Doglioli, A., De Verneil, A., and Bonnet, S.: Preface: The Oligotrophy to the UlTra-oligotrophy PACific Experiment (OUTPACE cruise, 18 February to 3 April 2015), 
Biogeosciences, 14, 3207-3220, https://doi.org/10.5194/bg-143207-2017, 2017.

Orchard, E. D., Webb, E. A., and Dyhrman, S. T.: Molecular analysis of the phosphorus starvation response in Trichodesmium spp., Environ. Microbiol., 11, 2400-2411, https://doi.org/10.1111/j.1462-2920.2009.01968.x, 2009.

Paerl, H. W. and Bebout, B. M.: Direct measurement of $\mathrm{O}_{2}$-depleted microzones in marine Oscillatoria: Relation to $\mathrm{N}_{2}$ fixation, Science, 241, 442-445, 1988.

Paerl, H. W., Bebout, B. M., and Prufert, L. E.: Bacterial associations with marine Oscillatoria sp. (Trichodesmium sp.) populations: ecophysiological implications, J. Phycol., 25, 773-784, 1989.

Peng, Y., Leung, H. C. M., Yiu, S. M., and Chin, F. Y. L.: IDBA-UD: a de novo assembler for single-cell and metagenomic sequencing data with highly uneven depth., Bioinformatics, 28, 1420-1428, https://doi.org/10.1093/bioinformatics/bts174, 2012.

Polyviou, D., Hitchcock, A., Baylay, A. J., Moore, C. M., and Bibby, T. S.: Phosphite utilisation by the globally important marine diazotroph Trichodesmium, Environ. Microbiol. Rep., 7, 827-830, https://doi.org/10.1111/1758-2229.12308, 2015.

Polyviou, D., Baylay, A. J., Hitchcock, A., Robidart, J., Moore, C. M., and Bibby, T. S.: Desert dust as a source of iron to the globally important diazotroph Trichodesmium, Front. Microbiol., 8, 1-12, https://doi.org/10.3389/fmicb.2017.02683, 2018.

Price, M. N., Dehal, P. S., and Arkin, A. P.: FastTree 2 - Approximately maximum-likelihood trees for large alignments, PLoS One, 5, https://doi.org/10.1371/journal.pone.0009490, 2010.

Pulido-Villena, E., Rérolle, V., and Guieu, C.: Transient fertilizing effect of dust in P-deficient LNLC surface ocean, Geophys. Res. Lett., 5, L01603, https://doi.org/10.1029/2009GL041415, 2010.

Repeta, D. J., Ferrón, S., Sosa, O. A., Johnson, C. G., Repeta, L. D., Acker, M., Delong, E. F., and Karl, D. M.: Marine methane paradox explained by bacterial degradation of dissolved organic matter, Nat. Geosci., 9, 884-887, https://doi.org/10.1038/ngeo2837, 2016.

Rouco, M., Joy-Warren, H., McGillicuddy, D. J., Waterbury, J. J. B., and Dyhrman, S. T.: Trichodesmium sp. clade distributions in the western North Atlantic Ocean, Limnol. Oceanogr., 59, 18991909, https://doi.org/10.4319/lo.2014.59.6.1899, 2014.

Rouco, M., Haley, S. T., Alexander, H., Wilson, S. T., Karl, D. M., and Dyhrman, S. T.: Variable depth distribution of Trichodesmium clades in the North Pacific Ocean, Environ. Microbiol. Rep., 8, 1058-1066, https://doi.org/10.1111/17582229.12488, 2016a.

Rouco, M., Haley, S. T., and Dyhrman, S. T.: Microbial diversity within the Trichodesmium holobiont, Environ. Microbiol., 18, 5151-5160, https://doi.org/10.1111/1462-2920.13513, $2016 \mathrm{~b}$.

Rouco, M., Frischkorn, K. R., Haley, S. T., Alexander, H., and Dyhrman, S. T.: Transcriptional patterns identify resource controls on the diazotroph Trichodesmium in the Atlantic and Pacific oceans, ISME J., 12, 1486-1495, https://doi.org/10.1038/s41396-018-0087-z, 2018.

Sañudo-Wilhelmy, S. A., Kustka, A. B., Gobler, C. J., Hutchins, D. A., Yang, M., Lwiza, K., Burns, J., Capone, D. G., Raven, J. A., and Carpenter, E. J.: Phosphorus limitation of nitrogen fixation by Trichodesmium in the central Atlantic Ocean., Nature, 411, 66-69, https://doi.org/10.1038/35075041, 2001.
Sargent, E. C., Hitchcock, A., Johansson, S. A., Langlois, R., Moore, C. M., LaRoche, J., Poulton, A. J., and Bibby, T. S.: Evidence for polyploidy in the globally important diazotroph Trichodesmium, FEMS Microbiol. Lett., 363, 1-7, https://doi.org/10.1093/femsle/fnw244, 2016.

Snow, J. T., Polyviou, D., Skipp, P., Chrismas, N. A. M., Hitchcock, A., Geider, R., Moore, C. M., and Bibby, T. S.: Quantifying integrated proteomic responses to iron stress in the globally important marine diazotroph Trichodesmium, PLoS One, 10, e0142626, https://doi.org/10.1371/journal.pone.0142626, 2015.

Sohm, J. A., Webb, E. A., and Capone, D. G.: Emerging patterns of marine nitrogen fixation., Nat. Rev. Microbiol., 9, 499-508, https://doi.org/10.1038/nrmicro2594, 2011.

Stenegren, M., Caputo, A., Berg, C., Bonnet, S., and Foster, R. A.: Distribution and drivers of symbiotic and free-living diazotrophic cyanobacteria in the Western Tropical South Pacific, Biogeosciences Discuss., 1-47, https://doi.org/10.5194/bg-201763, 2017.

Suzek, B. E., Huang, H., McGarvey, P., Mazumder, R., and $\mathrm{Wu}, \mathrm{C} . \mathrm{H} .:$ UniRef: comprehensive and non-redundant UniProt reference clusters, Bioinformatics, 23, 1282-1288, https://doi.org/10.1093/bioinformatics/btm098, 2007.

Van Mooy, B. A. S., Fredricks, H. F., Pedler, B. E., Dyhrman, S. T., Karl, D. M., Koblížek, M., Lomas, M. W., Mincer, T. J., Moore, L. R., Moutin, T., Rappé, M. S., and Webb, E. A.: Phytoplankton in the ocean use non-phosphorus lipids in response to phosphorus scarcity, Nature, 457, 69-72, 2009.

Van Mooy, B. A. S., Krupke, A., Dyhrman, S. T., Fredricks, H. F., Frischkorn, K. R., Ossolinski, J. E., Repeta, D. J., Rouco, M., Seewald, J. D., and Sylva, S. P.: Major role of planktonic phosphate reduction in the marine phosphorus redox cycle, Science, 348, 783-785, 2015.

Villarreal-Chiu, J. F.: The genes and enzymes of phosphonate metabolism by bacteria, and their distribution in the marine environment, Front. Microbiol., 3, 1-13, https://doi.org/10.3389/fmicb.2012.00019, 2012.

Walworth, N. G., Fu, F.-X., Lee, M. D., Cai, X., Saito, M. A., Webb, E. A., and Hutchins, D. A.: Nutrient co-limited Trichodesmium as nitrogen source or sink in a future ocean, Appl. Environ. Microbiol., 84, AEM.02137-17, https://doi.org/10.1128/AEM.0213717, 2017.

Wu, Y., Simmons, B. A., and Singer, S. W.: MaxBin 2.0: an automated binning algorithm to recover genomes from multiple metagenomic datasets, Bioinformatics, 32, 605-607, https://doi.org/10.1093/bioinformatics/btv638, 2015.

Yong, S. C., Roversi, P., Lillington, J., Rodriguez, F., Krehenbrink, M., Zeldin, O. B., Garman, E. F., Lea, S. M., and Berks, B. C.: A complex iron-calcium cofactor catalyzing phosphotransfer chemistry, Science, 345, 1170-1173, https://doi.org/10.1126/science.1254237, 2014.

Yu, X., Doroghazi, J. R., Janga, S. C., Zhang, J. K., Circello, B., Griffin, B. M., Labeda, D. P., and Metcalf, W. W.: Diversity and abundance of phosphonate biosynthetic genes in nature, P. Natl. Acad. Sci. USA, 110, 20759-20764, https://doi.org/10.1073/pnas.1315107110, 2013. 